\title{
Redox Regulation of Heme Oxygenase-2 and the Transcription Factor, Rev-Erb, Through Heme Regulatory Motifs
}

\author{
Angela S. Fleischhacker, Eric L. Carter, and Stephen W. Ragsdale
}

\begin{abstract}
Significance: Heme binds to and serves as a cofactor for a myriad of proteins that are involved in diverse biological processes. Hemoproteins also exhibit varying modes of heme binding, suggesting that the protein environment contributes to the functional versatility of this prosthetic group. The subject of this review is a subset of hemoproteins that contain at least one heme regulatory motif (HRM), which is a short sequence containing a Cys-Pro core that, in many cases, binds heme with the Cys acting as an axial ligand.

Recent Advances: As more details about HRM-containing proteins are uncovered, some underlying commonalities are emerging, including a role in regulating protein stability. Further, the cysteines of some HRMs have been shown to form disulfide bonds. Because the cysteines must be in the reduced, dithiol form to act as a heme axial ligand, heme binds at these sites in a redox-regulated manner, as demonstrated for heme oxygenase- 2 (HO2) and $\operatorname{Rev}-\operatorname{erb} \beta$.

Critical Issues: HRM-containing proteins have wide variations in heme affinity, utilize different axial ligand schemes, and exhibit differences in the ability to act as a redox sensor-all while having a wide variety of biological functions. Here, we highlight $\mathrm{HO} 2$ and $\operatorname{Rev}-\operatorname{erb} \beta$ to illustrate the similarities and differences between two hemoproteins that contain HRMs acting as redox sensors.

Future Directions: HRMs acting as redox sensors may be applicable to other HRM-containing proteins as many contain multiple HRMs and/or other cysteine residues, which may become more evident as the functional significance of HRMs is probed in additional proteins. Antioxid. Redox Signal. 29, 1841-1857.
\end{abstract}

Keywords: heme, heme regulatory motif, disulfide, redox regulation, heme oxygenase, nuclear receptor

\section{Introduction}

T He heme Regulatory MOTIF (HRM) is a short sequence containing a Cys-Pro core that, in many cases, binds heme with the Cys acting as an axial ligand. HRMs are found in a diverse set of proteins that have a wide variety of biological functions, but the study of HRMs began in earnest only relatively recently. In 1989, the DNA sequence of heme activator protein 1 (Hap-1), a yeast transcription activator, revealed a short sequence (Lys/Arg-Cys-Pro-Val/Ile-AspHis) repeated six times over an $\sim 200$ amino acid section of the protein that modulated DNA binding in response to heme (67). Then, in 1993, three copies of a similar sequence (Arg/ Ser-Cys-Pro-Val/Ile-Leu-Ala) were identified by Lathrop and Timko in the precursor protein sequence of both the nonspecific (ALAS1) and erythroid-specific (ALAS2) forms of $\delta$-aminolevulinic acid synthase. Two copies are located in the presequence for mitochondrial translocation that is proteolytically removed on import to form the mature protein, and mutation of both Cys residues to Ser in those copies eliminated the heme-dependent inhibition of mitochondrial transport of mouse ALAS2 (52). Thus, the name "heme regulatory motif" was bestowed on the short sequence by the authors of the report, and they additionally noted the presence of HRMs in sequences of catalase and hemopexin. Two years later, Zhang and Guarente also referred to the short sequences in Hap- 1 as HRMs and identified HRMs in heme-regulated eIF $2 \alpha$ kinase (HRI), heme lyase, and heme oxygenase-2 (HO2) (105).

Department of Biological Chemistry, University of Michigan, Ann Arbor, Michigan. 
The Zhang and Guarente report was much more defining to the field than simply cementing a name for the motif. First, an alignment of the sequences around the Cys-Pro dipeptide showed a tendency for a basic residue before the Cys and a hydrophobic residue after Pro (105), helping to define an HRM. Second, the report provided spectroscopic evidence of direct heme binding to a short peptide (Ala-Lys-Arg-CysPro-Val-Asp-His-Thr-Met) corresponding to the consensus of the six HRMs of Hap-1 (105). Finally, based on mutational studies (Cys to Ala and Pro to Ala) of Hap-1, it was proposed that $\mathrm{Cys}$ acts as an axial ligand to $\mathrm{Fe}^{3+}$-heme and that Pro plays a structural role, possibly by exposing Cys for ligation (105). Thus, the study included several key factors in initially defining what an HRM is and how the motifs would be studied in the future.

The report also demonstrated that not all HRMs are created equal. The authors identified a seventh HRM (HRM7) in Hap-1 located near the activation domain closer to the Cterminus of the protein (the first six HRMs are located near the N-terminal DNA-binding domain) and demonstrated that it is HRM7 that modulates the activation of Hap-1 in response to heme (105), a finding that was confirmed by later studies that pointed to only a minor role of the other HRMs despite the ability of the peptide to bind heme $(28,33)$. Thus, given these findings on Hap-1 and ALAS2 demonstrating that HRMs even in the same protein can function differently, it became clear, and is one of the themes in this review, how important it is to characterize the function of the hemebinding event and to assess (as quantitatively as possible) heme binding to a designated HRM.

\section{The functions assigned to HRMs}

Assigning a function to a particular HRM is of great interest to those who study HRM-containing proteins. There does not appear to be one common function assignable to the HRMs - and it is believed that some HRMs have no functional relevance-so each HRM must be investigated thoroughly. Further, proteins that contain HRMs are varied, including transcription factors and enzymes involved in many different processes. Thus, the field includes a wide variety of approaches to study HRM-containing proteins, which has, in turn, led to the uncovering of a variety of effects of heme binding to an HRM (Fig. 1).

Despite a common function not having been assigned to HRMs, there are several examples of HRMs promoting heme-dependent protein degradation. The nuclear receptor (NR) Rev-erb $\beta$, which represses the transcription of genes involved in regulating circadian rhythms and is described in detail later, is degraded in a heme-dependent manner (9). Heme binding to human Period-2 targets the protein for degradation, likely through the ubiquitin-proteasome pathway, and prevents formation of the heterodimeric complex between period- 2 and human cryptochrome 1 that is involved in the regulation of circadian rhythms (94). Heme binding to tumor suppressor protein and metabolic regulator, p53, interferes with the ability of the protein to interact with DNA (14) (Fig. 2) and facilitates its nuclear export for cytosolic degradation (79). Similarly, the ability of Bach1, which regulates the expression of heme oxygenase-1 (HO1), to bind to DNA is significantly decreased on heme binding, which also targets Bach1 for nuclear export, polyubiquitination, and degradation $(65,82,85,103)$. Bradyrhizobium japonicum iron response regulator (Irr) regulates iron homeostasis and metabolism by acting as a repressor under low iron conditions and, under high iron conditions, is degraded on heme binding, allowing transcription to proceed $(69,97)$. Irr binds heme at both an HRM and a His-cluster site (His-His-His sequence) (39), and the protein appears to be degraded in a mechanism involving both sites that results in oxidative modification of the protein $(46,95,96)$. ALAS1, the nonspecific form of $\delta$ aminolevulinic acid synthase that catalyzes the first step of heme biosynthesis, contains three HRMs: two in the presequence involved in mitochondrial import (HRM1 and HRM2) and one near the N-terminus of the mature protein (HRM3) (52). HRM1 and HRM3 of rat ALAS1 were shown through mutagenesis studies to be critical for the hemedependent inhibition of mitochondrial import (63). In addition, HRM3 of human ALAS1 was recently shown to be required for the heme-dependent formation of an ALAS1/ ClpXP complex as well as for the oxidative modification of ALAS1 that triggers recruitment of LONP1, an ATPdependent protease (48). Heme-dependent degradation on heme binding to HRMs has also been proposed for iron regulatory protein 2 (IRP2), a regulator of iron metabolism (38), and arginyl-transferase, which conjugates arginine to the $\mathrm{N}$-terminus of proteins as a part of the $\mathrm{N}$-end rule of protein degradation (35).

In contrast to the examples provided earlier of HRMs participating in heme-dependent protein degradation are the HRM-containing proteins Hap-1 and HRI. Hap-1, briefly discussed earlier as one of the proteins in which HRMs were initially identified, activates the transcription of genes involved in respiration and the control of oxidative damage in yeast in response to heme. Heme binding to HRM7 of Hap-1 promotes the transition of a high-molecular-weight complex containing Hap-1 and several other proteins to a Hap-1 homodimer that binds DNA with a high affinity (106). Recently, it has been shown that Hap-1 represses transcription of its own gene and several others in the absence of heme $(32,34)$, making the HRM of Hap-1 an important sensor of heme levels in yeast. HRI also appears to be a sensor of intracellular heme levels. However, heme binding to HRI at an HRM promotes the transition from an active to an inactive state. It is when reticulocytes are heme deficient that HRI (without heme bound to the HRM) autophosphorylates and, subsequently, phosphorylates eIF $2 \alpha$ to downregulate protein synthesis, particularly globin synthesis $(12,37,62)$.

In addition to the examples listed earlier, there are many more HRM-containing proteins in which the function of heme binding is unclear. For example, in contrast to what Lanthrop and Timko reported on the function of HRMs in mouse ALAS2 (52), a subsequent study showed no effect of heme on mitochondrial import of rat ALAS2 (63); thus, the relevance of the HRM is questioned. In addition, there are examples of proteins for which the function of the HRM remains elusive: $\mathrm{HO} 2$, which will be described in detail later; stanniocalcin-2, a glycoprotein shown to interact with HO1 (42); and DiGeorge critical region 8 (DGCR8), a protein involved in the first step of microRNA processing that appears to bind heme at a Pro-Cys (rather than Cys-Pro) site (19). Lastly, using a combinatorial peptide library approach, several other proteins were recently identified as having 


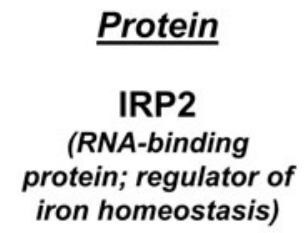

Irr

(Fur homolog; couples iron availability and heme synthesis)
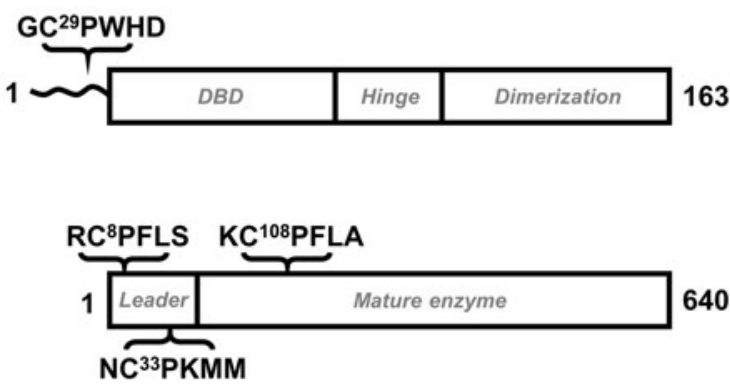

$\underline{\text { Heme } H R M \text { function }}$

Promote oxidative

modification and

degradation

\section{Promote degradation}

\author{
Regulation of \\ mitochondrial import \\ and degradation
} and metabolic genes)

$\mathrm{HO} 2$ (converts heme to biliverdin, $\mathrm{CO}$, and iron)

HAP-1 (transcription activator in yeast, regulator of respiratory proteins)

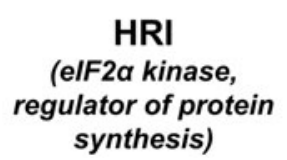
Redox regulation of heme affinity, corepressor binding and degradation
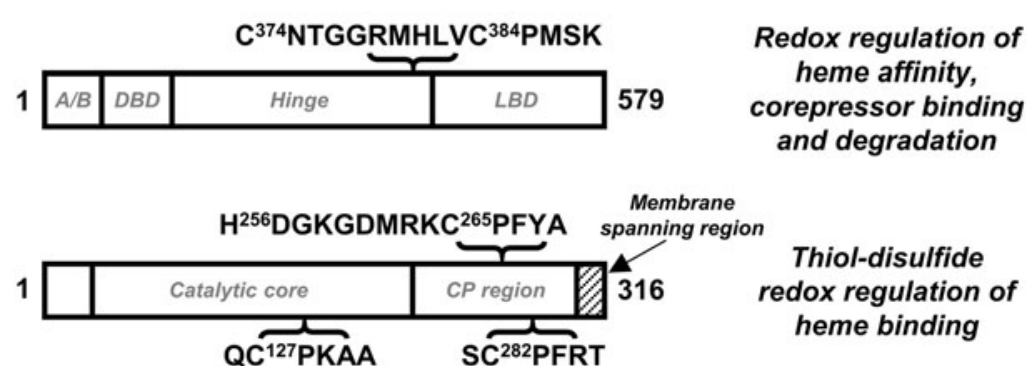

6X: (K/R)-C-P-(I/V)-(N/D)-H

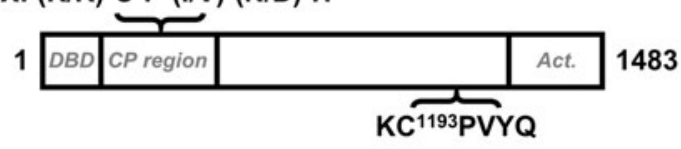
Promote DNA binding and activation of target genes

Inhibition of kinase activity

FIG. 1. HRMs regulate the activity of enzymes, transcription factors, and an RNA regulatory protein. The modular structure of HRM-containing proteins is shown, along with the context and sequence of the HRMs. Domain organization (1-4) of IRP2 is based on its homology to aconitase $(41,74)$. Similarly, Irr is homologous to the Ferric Uptake Regulator (Fur) from Pseudomonas aeruginosa, and its domains are tentatively assigned as such; the $\mathrm{N}$-terminal region of Irr that is distinct from Fur and contains the HRM is shown as a wavy line (29). The sequence of $\operatorname{Rev}-\operatorname{erb} \beta$ containing the HRM and redox-active Cys374 is shown; the A/B domain is hypervariable among members of the NR superfamily. For HO2, the sequence encompassing the heme ligand, His256 is shown in context to the nearby HRM. Hap-1 domain organization is based on functional studies (67); Act. refers to the domain that imparts transcription activation activity. NTD, or N-terminal domain of HRI is important for regulating quaternary structure (62). Delineation of domain boundaries are approximations. ALAS1, aminolevulinic acid synthase-1 nonspecific; Hap-1, heme activator protein-1; HO2, heme oxygenase isoform 2; HRM, heme regulatory motif; IRP2, iron regulatory protein 2 ; Irr, bacterial iron response regulator.

potential HRMs that may bind heme $(6,49,50,77)$. The authors used high-throughput screening to identify hemebinding peptides, and their sequences were then searched against protein sequence databases to identify proteins that may bind heme. Dipeptidyl peptidase 8 [(DP8), a member of the serine proteases (104)], FeoB [a bacterial ferrous iron transport protein (44)], and interleukin-36 $[$ [(IL-36 $\alpha$ ), a cytokine that induces inflammatory responses (21)] were, among other proteins, identified. The results suggest that not all HRM-containing proteins have even been identified, so the full extent of neither the capabilities of HRMs nor the physiological links between heme levels and metabolic pathways is fully understood.

\section{Heme binding to HRMs}

A critical point in assigning a function to an HRMcontaining protein is to show direct heme binding to the HRM. Providing evidence of this HRM-heme interaction subsequently eliminates the possibility of indirect heme regulation and, particularly in the case of proteins such as Hap-1 (105) and Bach1 (65) that contain multiple HRMs, 
helps to distinguish responsive from unresponsive HRMs. Although X-ray crystal structures of only a few of the HRMcontaining proteins (and their heme-bound forms) have been reported (Fig. 2), heme and heme-bound species lend themselves well to a variety of spectroscopic methods.

The classic model of the heme-HRM interaction includes $\mathrm{Fe}^{3+}$ of the heme in a penta-coordinated state with Cys acting an axial ligand. A shift in the absorbance of $\mathrm{Fe}^{3+}$-heme in aqueous solution from $\sim 385 \mathrm{~nm}$ to $\sim 370 \mathrm{~nm}$ in the presence of the HRM-containing peptide or protein is characteristic of
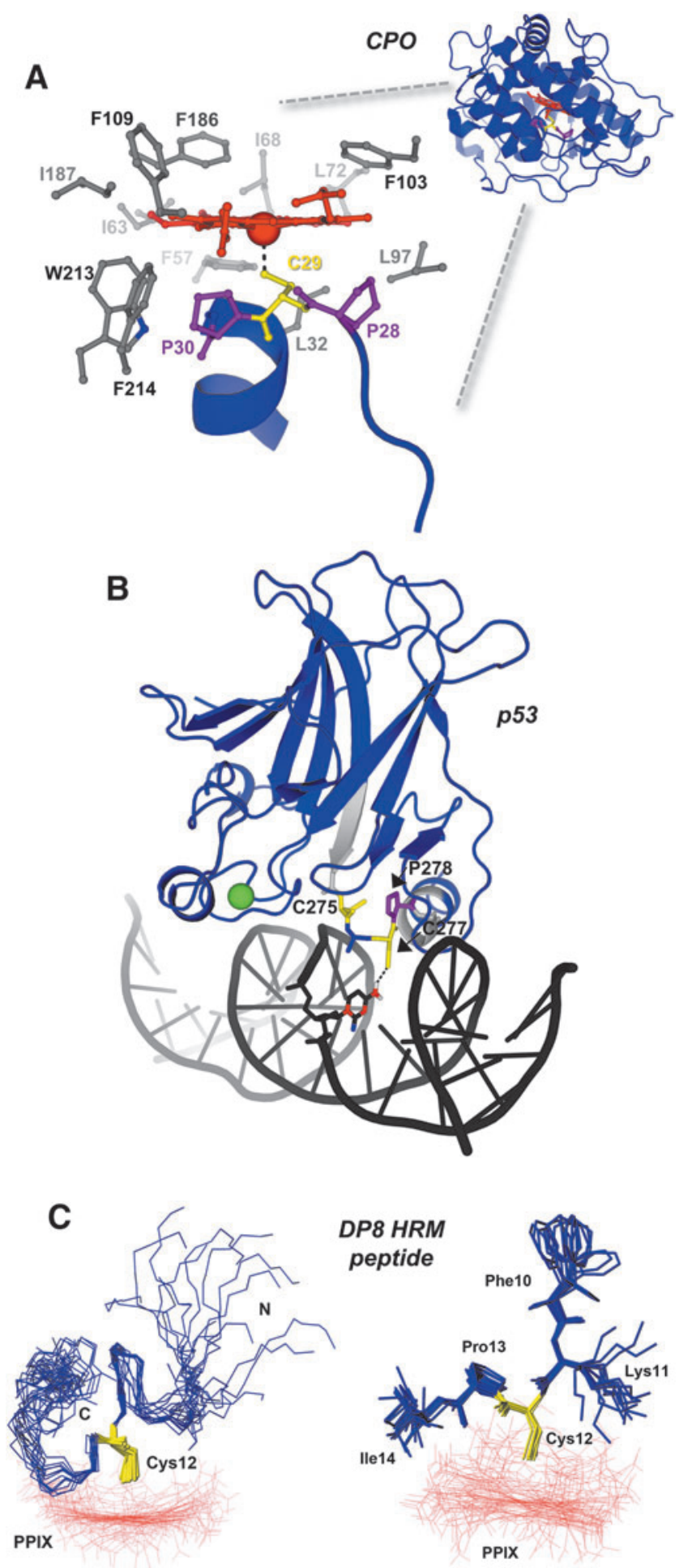

$\mathrm{Fe}^{3+}$-heme binding to an HRM in this manner (105). Such complexes have an electron paramagnetic resonance (EPR) signal at $g \sim 6$, although the signal is often broadened as compared with the signal for free $\mathrm{Fe}^{3+}$-heme in solution (39, 77 ), as shown later in the UV-vis and EPR spectra of some specific HRMs. Other spectroscopic methods such as resonance Raman $(39,50,77)$, electron nuclear double resonance (ENDOR) (2), extended X-ray absorption fine structure (EXAFS) (2), and X-ray absorption (XAS) (2) have demonstrated Cys ligation of heme at HRMs and assisted in the characterization of the heme-HRM interaction.

Structural data available for HRM-containing peptides and proteins provide insights into how heme binds at these sites. Chloroperoxidase (CPO) is a versatile enzyme that uses heme to catalyze a variety of oxidative reactions: halogenation, dehydrogenation (heme peroxidase-like activity), hydrogen peroxide decomposition (catalase-like activity), and oxygen insertion (cytochrome P450-like activity). The structure of CPO shows the heme bound within an 8-helix bundle; the proximal side resembles cytochrome $\mathrm{P} 450$ and provides an axial thiolate (cysteine) ligand, whereas the distal side contains polar residues that form the peroxide-binding site, like other peroxidases (Fig. 2) (84). The Cys ligand in CPO resides within an unusual Pro-Cys-Pro motif on a helix that is nearly perpendicular to the heme plane, and the two prolines position the Cys for ligation to the heme. The only access to the $\mathrm{Fe}^{3+}$-heme is in the distal face, allowing only small organic substrates to interact with an iron-linked oxygen atom, accounting for its P450-like reaction. Another example of an HRM in a structured region is the Cys275-X-Cys277-Pro motif of the transcription factor, p53, which lies at the interface of the protein and its cognate DNA element (14) (Fig. 2). Cys 277 of the HRM accepts a hydrogen bond from a nearby cytosine, but it is also responsible for binding heme

FIG. 2. HRMs provide unique structural determinants to proteins and enzymes. (A) The overall structure of chloroperoxidase (PDB: 2ciw) shows that the HRM and $\mathrm{Fe}^{3+}$-heme cofactor are buried within the enzyme. A close-up view of the active site highlights the unique Pro-Cys-Pro HRM of CPO (prolines are shown as purple sticks, cysteine as yellow sticks), which positions the axial thiolate for heme ligation. Nonpolar residues within $4 \AA$ of heme are shown as gray sticks. (B) p53, a transcription factor and tumor suppressor, is shown to be complexed with its cognate DNA promoter element (PDB: 1tsr). Residues flanking the HRM are shown as light gray cartoons to highlight the region, and a structural zinc atom is shown as a green sphere. (C) The NMR structure of an HRM-containing peptide from DP8 in complex with $\mathrm{Ga}^{3+}$-PPIX. Left panel, the 15 structures of lowest target function are shown with the peptide backbone as blue sticks, the HRM Cys12 in yellow sticks, and $\mathrm{Ga}^{3+}$-PPIX as red lines; the right panel depicts the inflexibility of the Cys-Pro core versus the side chains of surrounding residues. The structure serves as an excellent model demonstrating how the HRM Pro residue positions C-terminal residues away from heme, while poising the Cys-thiolate to act as a heme axial ligand. The structure of an IL-36 $\alpha$-derived HRM peptide in complex with $\mathrm{Ga}^{3+}$-PPIX recapitulates many of the features observed with the DP8 peptide (6). Figures in (C) are reprinted (adapted) with permission from Kühl et al. (50). Copyright (2013) American Chemical Society. CPO, chloroperoxidase; DP8, dipeptidyl peptidase 8; IL-36 $\alpha$, interleukin-36 $\alpha$; NMR, nuclear magnetic resonance; PPIX, protoporphyrin IX. 
along with neighboring C275 (14, 79). High heme levels drive binding to Cys275 and Cys277 and cause p53 dissociation from DNA, likely by disrupting the DNA:p53 hydrogen bond network.

In contrast, a number of HRMs are within disordered regions, as represented by the nuclear magnetic resonance (NMR) structures of two peptides spanning the HRMcontaining regions of DP8 (Fig. 2) and IL-36 $\alpha(6,50)$. UV-vis, EPR, and resonance Raman spectroscopies demonstrated that both a 23-mer peptide (SGGLPAPSDFKCPIKEEEIAITSG) spanning residues S495-G517 of DP8 and a 9-mer peptide (SEGGCPLIL) spanning the HRM of IL-36 $\alpha$ bound $\mathrm{Fe}^{3+}$ -heme in a penta-coordinated state, with Cys acting as an axial ligand $(6,50,77)$. Using gallium(III) protoporphyrin IX
(PPIX), a diamagnetic $\mathrm{Fe}^{3+}$-heme mimic (5), the authors were able to show that structural definition is introduced on $\mathrm{Ga}(\mathrm{III})$ PPIX binding only to the central amino acids around Cys and that Pro positions the Cys for axial ligation while positioning the C-terminal residues away from Ga(III) PPIX for both DP8 and IL-36 $\alpha$ peptides $(6,50)$. The surface binding of $\mathrm{Ga}$ (III) PPIX to the peptides, in contrast to the more structured and less solvent-exposed $\mathrm{Fe}^{3+}$-heme-binding pocket of CPO (Fig. 2), is consistent with HRMs being found in unstructured regions, such as in $\mathrm{HO} 2(2)$.

The HRM of $\operatorname{Rev}-\operatorname{erb} \beta$ is also in a flexible unstructured loop, but, in contrast to the structures of CPO and the DP8 peptide, His and Cys act as axial ligands to $\mathrm{Fe}^{3+}$-heme (Fig. 3) (66). Although the structure will be discussed in greater detail
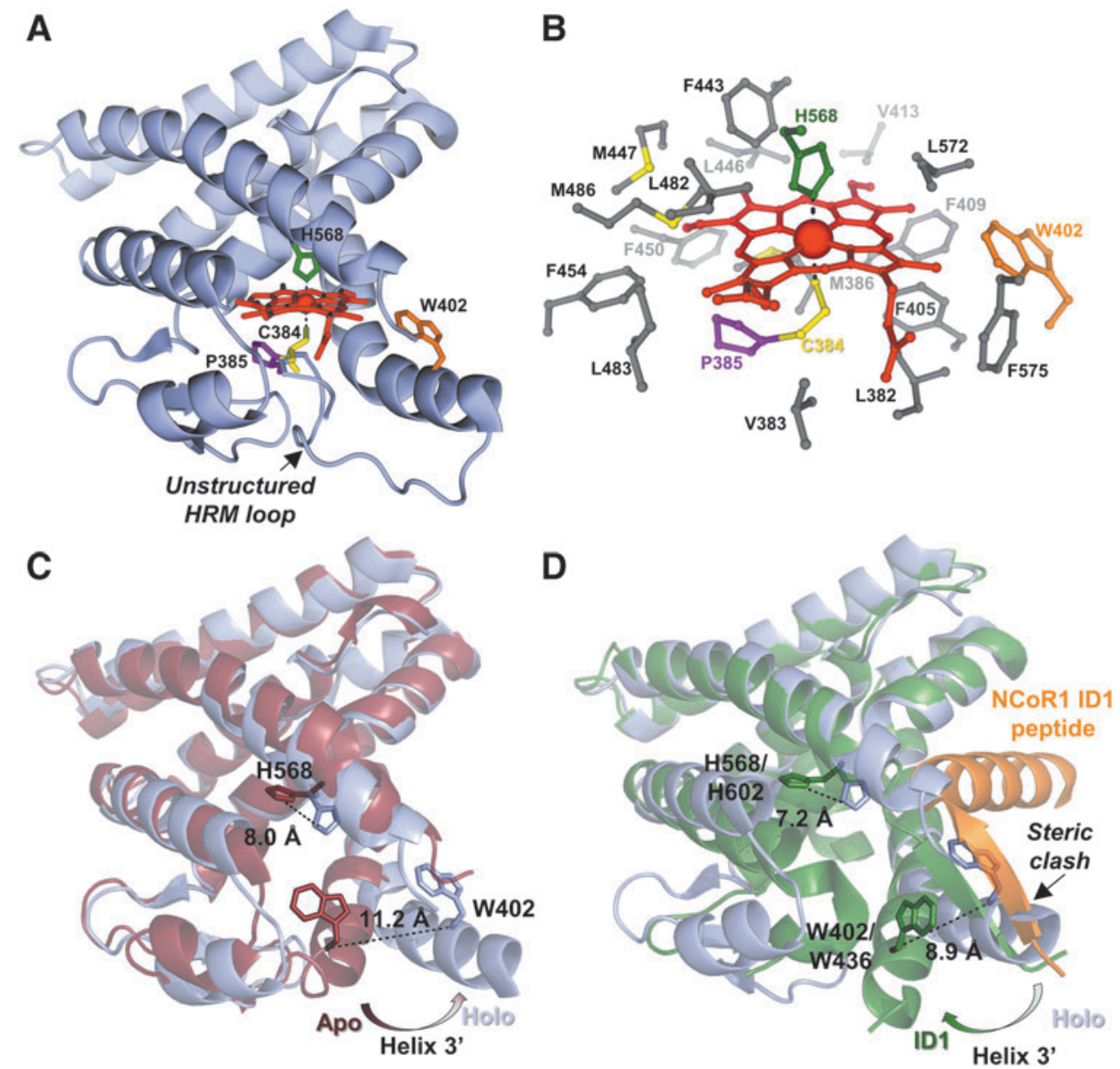

FIG. 3. Structural insight into HRM-mediated redox regulation of heme binding to nuclear receptor, Rev-erb $\beta$. (A) Structure of the Rev-erb $\beta$ LBD in complex with $\mathrm{Fe}^{3+}$-heme (holo-LBD, PDB: $3 \mathrm{cqv}$ ). Heme binds in a 6-coordinate, low-spin complex with His (H568, green sticks) and Cys (C384, yellow sticks) axial ligands. C384 and P385 (purple sticks) comprise an HRM core that resides on a flexible, unstructured loop. W402 (orange sticks) provides hydrophobic contacts to heme, and its fluorescence is quenched on heme binding (unpublished observations). (B) The Rev-erb $\beta$ heme pocket is highly hydrophobic with nonpolar residues within $4 \AA$ of heme shown as gray sticks (66). (C) Heme binding induces conformational changes of the LBD. Overlay of apo-LBD (dark red; PDB: 2v0v) and holo-LBD (light blue) structures aligned in Pymol; heme and the flexible HRM-harboring loop from the holo-LBD structure are omitted for clarity. The H3' helix swings out to accommodate the porphyrin ring, leading to a $11.2 \AA$ shift of the W402 $\alpha$-carbon. Further, conformational changes in helix 11 cause the $\tau$-nitrogen of $\mathrm{H} 568$ to shift $8.0 \AA$, and assume its role as a $\mathrm{Fe}^{3+}$-heme ligand. (D) Pymol structural alignment of holo-LBD (light blue) versus apo-Rev-erb $\alpha$ LBD (dark green) in complex with an NCoR1 ID1 peptide (orange), PDB: 3n00; again, heme and the HRM loop are omitted for clarity. An anti-parallel beta sheet formed between an unraveled portion of Rev-erb $\alpha$ helix 11 and the NCoR1 peptide exhibits steric clash with helix H3' in the holo-LBD structure. Further, the heme axial ligand, H602 in Rev-erb $\alpha$ pivots away from the heme-binding pocket, suggesting that heme and NCoR1 would compete for different Reverb conformers. ID, interaction domain; LBD, ligand-binding domain; NCoR1, nuclear receptor compressor 1. 
later, it demonstrates that $\mathrm{Fe}^{3+}$-heme bound to HRMs can also be hexa-coordinated. In fact, a growing number of proteins have been shown to bind $\mathrm{Fe}^{3+}$-heme at their HRM as a hexacoordinated complex with Cys and an additional protein residue, usually His, acting as axial ligands. In addition to Rev-erb $\beta$, HRI $(37,62)$ and HO2 (20) also bind $\mathrm{Fe}^{3+}$-heme with Cys and His ligands. These proteins have characteristic absorbance at $\sim 420 \mathrm{~nm}$ and a low-spin rhombic EPR signal with $g$-values of 2.5, 2.3, and 1.9. Resonance Raman has also been shown to be useful in distinguishing penta- and hexacoordination $(39,50)$.

Although spectroscopy may simplify the assignment of the ligands as Cys and His, actually identifying the His residue can be a challenge. In each of the three examples- $-\operatorname{Rev}-\operatorname{erb} \beta$, $\mathrm{HRI}$, and HO2 - the His is located far outside of the Cys-Pro sequence motif of the HRM. Further, likely due to the surface binding of $\mathrm{Fe}^{3+}$-heme to some HRMs rather than in a more defined binding pocket, $\mathrm{Fe}^{3+}$-heme binds to some HRMcontaining proteins in multiple conformations. For example, $\mathrm{Fe}^{3+}$-heme bound to the HRM of Irr is in a mixture of pentaand hexa-coordinated states (39), complicating the assignment of ligands. A mixture of states was also observed for several peptides used in recent combinatorial peptide library studies $(6,49,50,77)$. For instance, an $\mathrm{Fe}^{3+}$-heme-bound peptide, TPILCPFHL, based on the sequence of IRP2 displayed UVvis absorbance, EPR, and resonance Raman spectra consistent with a mixture of penta- and hexa-coordinated $\mathrm{Fe}^{3+}$-heme. The NMR structure of the Ga(III) PPIX-bound peptide is in the penta-coordinated state, but by the admission of the authors, there is insufficient distance between the Cys and His to form a hexa-coordinated species unless a second peptide were present (6). The histidine in this peptide corresponds to His204 in the protein, and this residue is not involved in $\mathrm{Fe}^{3+}$-heme binding to Cys201 of the HRM. Rather, His204 is postulated to be necessary for protein degradation and the binding of $\mathrm{Fe}^{2+}$-heme (38). Indeed, the spacing between the HRMs and the His residues that act as axial ligands in proteins such as Rev-erb $\beta$, HRI, and $\mathrm{HO} 2$ would be difficult to mimic with short peptides.

Although most of the HRMs that bind $\mathrm{Fe}^{3+}$-heme in the hexa-coordinated state use Cys and His as axial ligands, one example of a protein that does not is DGCR8. As mentioned earlier, the sequence of the HRM of DGCR8 is Pro-Cys, rather than Cys-Pro. Spectroscopic studies have concluded that DGCR8 binds $\mathrm{Fe}^{3+}$-heme with an unusual ligand arrangement of two Cys axial ligands (3). $\mathrm{Fe}^{3+}$-heme is postulated to bind at a dimer interface with the Cys of an HRM from each monomer acting as an axial ligand. Two Cys ligands are not likely to be a common ligation environment for heme, but the example of DGCR8 is given here to emphasize that since not all HRM-containing proteins have been characterized, protein residues other than His can be the sixth ligand to hexa-coordinated $\mathrm{Fe}^{3+}$-heme bound to HRMs.

\section{HRMs and redox chemistry}

This review focuses on $\operatorname{Rev}-\operatorname{erb} \beta$ and $\mathrm{HO} 2$, which have been extensively studied in our laboratory, leading to characterization of the function and the various modes of heme binding to HRMs. In both Rev-erb $\beta$ and HO2, the HRMs act as redox sensors in which the Cys residues form disulfide bonds, altering the affinity of the HRM for heme. Although this has thus far only been noted for Rev-erb $\beta$ and HO2, many HRM-containing proteins contain multiple HRMs and/or other Cys that may be available to form disulfide bonds. Therefore, by highlighting these two very different proteins, we hope to contribute to a more general understanding of HRMs and their potential link to the redox state of the cell.

\section{Rev-Erb}

\section{Regulation of circadian rhythms by heme}

Mammals are entrained to the diurnal cycle through light perception, a signal that is transduced via the optic nerve to the suprachiasmatic nucleus ( $\mathrm{SCN})$, a small region of the brain located at the optic chiasm $(73,76)$. Within the SCN, a set of core molecular clock proteins synchronize cellular processes through activation and repression of gene transcription. At the apex of the molecular clock are the Bmall and $C L O C K$ genes, whose protein products form a heterodimeric complex that binds to the promoters of clockcontrolled genes to activate transcription. Among those genes activated are Period 1, 2, and 3, Cryptochrome 1 and 2, and Rev-erb $\alpha$ and Rev-erb $\beta$. Period (Per) and Cryptochrome (Cry) proteins form a complex that inhibits the activator function of Bmal1 $\bullet$ CLOCK, whereas Rev-erbs repress the transcription of Bmall and CLOCK genes. Together, Per, Cry, and Rev-erbs comprise the negative limb of the molecular clock that completes the feedback loop required for circadian rhythm maintenance (47).

The interplay of heme with the molecular clock is emerging as an important signaling axis. For example, heme biosynthesis and intracellular heme levels are entrained to the clock through regulation of ALAS1 by the Bmall•NPAS2 (a forebrain CLOCK homolog) heterodimer (43). Significantly, NPAS2 is also a hemoprotein that binds carbon monoxide (CO), which further regulates its DNA-binding activity (17). On the negative limb of the circadian oscillator, Per2 contains an HRM that binds $\mathrm{Fe}^{3+}$-heme and promotes its degradation (94). Further, Per 2 expression is regulated by p53, another HRM-containing transcription factor and metabolic regulator as discussed earlier (61). Rev-erb $\alpha$ and $\beta$ isoforms also contain a redoxsensitive HRM that regulates heme binding, corepressor recruitment, and degradation $(9,11,27)$. Because heme plays an integral role in energy production and metabolism, controlled degradation of Per2, Rev-erbs, and p53 through heme binding to their HRMs effectively couples those processes to the molecular clock. In the next section, we will discuss in detail the heme-dependent activities of Rev-erbs, and how they relate to circadian rhythm maintenance and entrainment of metabolic, inflammatory, and differentiation pathways.

\section{Heme binding to Rev-erb $\alpha$ and Rev-erb $\beta$ indirectly facilitates corepressor recruitment}

Rev-erbs are transcription factors that belong to the NR superfamily, which includes receptors of thyroid, estrogen, and testosterone hormones. In the ligand-bound state, many NRs recruit transcription coactivator complexes with histone acetyltransferase activity that ultimately leads to target gene activation (25). Rev-erbs are unique to the superfamily in that they lack a structural determinant required for coactivator binding, rendering them as repressors of transcription (93). The $\alpha$ and $\beta$ isoforms share $>70 \%$ amino acid identity in their 
DNA- and ligand-binding domains (LBD), and they are highly redundant in terms of circadian expression patterns and their target genes $(8,13,18)$. Rev-erbs repress transcription either by direct competition for promoter elements with the transcription activator, RAR-related orphan receptor $(\operatorname{ROR} \alpha)$, or by interacting with nuclear receptor corepressor (NCoR1) $(1,8,13)$. NCoR1 is a $270 \mathrm{kDa}$ protein that acts as a scaffold bringing together NRs and histone deacetylase complexes that enhance repression (40). As discussed earlier, Rev-erbs have been well studied in their role as circadian factors, but they also repress the transcription of key genes involved in glucose and lipid metabolism, inflammatory responses, differentiation, and body temperature regulation, entraining these processes to the clock $(23,24,72,88,91,102)$.

In 2007, two independent groups identified heme as the endogenous ligand for Rev-erbs $(70,102)$. Estimates of Reverb $\alpha / \beta$ affinity for $\mathrm{Fe}^{3+}$-heme using isothermal titration calorimetry (ITC) were between 0.35 and $3.52 \mu M(59,70)$. Diminution of cellular heme levels with the ALA-dehydratase inhibitor, succinylacetone, reversed Rev-erb $\alpha$-dependent repression of target genes by disrupting the interaction of Reverb $\alpha$ with NCoR $1(70,102)$. There is also evidence that heme binding to both $\alpha$ and $\beta$ isoforms promotes their degradation likely through a ubiquitin-dependent pathway involving the E3-ligases, Arf-bp1, and Myc-bp2 (9, 51, 100). Based on these observations, a model was proposed in which Rev-erbs rapidly equilibrate with the regulatory heme $(\mathrm{RH})$ pool so that when heme levels are high, Rev-erbs exist as holoproteins bound to NCoR 1 and repress target gene transcription in a fine balance with their own degradation; controlling transcription output via degradation has also been observed with the thyroid hormone receptor (15). Presumably, low heme levels occlude binding to Rev-erbs based on the high $K_{\mathrm{d}}$ of the complex, leading to NCoR1 dissociation and relief of repression (Fig. 4). A potential problem with this model is that the apparent weak affinity for heme $\left(\mu M K_{\mathrm{d}}\right)$ coupled with very low free (or exchangeable) cellular heme levels $(<100 \mathrm{nM})$ would be inconsistent with the proposed (70) role of Rev-erbs as sensors of intracellular heme. The results of other in vitro studies indicated that the simple heme-based recruitment model was incomplete.

Despite congruity among the cellular results described earlier, structural and in vitro studies provided evidence contrary to the heme-dependent NCoR1 recruitment model. The structure of the $\mathrm{Fe}^{3+}$-heme $\bullet \mathrm{Rev}-\mathrm{erb} \beta$ complex shows heme bound in a six-coordinate system with axial ligands $\mathrm{H} 568$ and C384; the latter is provided by an HRM found on a flexible loop that is not present in the structure of the apoprotein (Fig. 3A, C) (66). The heme pocket is highly hydrophobic, stabilizing the nonpolar character of the porphyrin ring (Fig. 3B). Significant conformational changes are associated with heme binding to the apoprotein, namely a large shift of helix $3^{\prime}$ that opens the pocket to accommodate heme, a pivot of H568 to assume its position as a heme axial ligand, and the appearance of the disordered HRM loop that provides C384 (Fig. 3C) (93). More importantly, comparing the structures of the Rev-erb $\beta$ holoprotein to apoRev-erb $\alpha$ in complex with an NCoR1 peptide reveals a significant steric clash between helix 3 in the holoprotein structure and an antiparallel beta sheet formed between helix 11 of Rev-erb $\alpha$ and the NCoR1 peptide (Fig. 3D) (68). The axial His residue, $\mathrm{H} 602$ in Rev-erb $\alpha$, also swings out and away from the heme pocket in the NCoR1 structure, suggesting that heme and NCoR1 would not bind simultaneously to the LBD. Several in vitro studies supported the structural data and demonstrated that heme and cobalt-PPIX effectively compete with NCoR1 peptides for binding to purified Rev-erb $\alpha / \beta$ LBDs (59, 70, 102).

A potential caveat to the structural and in vitro studies was the use of truncated Rev-erb $\alpha / \beta$ LBDs and NCoR1 peptides that may not accurately represent the interactions between full-length proteins. For instance, the C-terminus of NCoR1 contains three NR interaction domains (IDs), two of which are known to associate with Rev-erb $\alpha$ (45); thus, the use of a single ID peptide for binding and structural studies may not be sufficient to promote cooperative interactions between different IDs on a single polypeptide. Thus, it seemed likely that contacts among the Rev-erb N-terminus, DNA-binding domain, and hinge region may impart unique biochemical properties and heme-dependent activities unobservable in experiments utilizing isolated LBDs.

To discover whether the in vitro and cellular experiments would coincide if we used the full-length Rev-erb instead of the LBD alone, we developed strategies to purify full-length Rev-erb $\beta$ (FLRev-erb $\beta$ ) and an NCoR 1 construct (instead of the short peptide) containing all three IDs (9). First, we found through the use of electromobility shift assays and UV-vis spectroscopy that heme and NCoR1, indeed, form a ternary complex with Rev-erb $\beta$ under equilibrium conditions, indicating the LBD is flexible in solution and can accommodate both ligands. However, heme was not required for the interaction of NCoR 1 with the FLRev-erb $\beta \bullet$ DNA complex in a purified system and heme does not promote NCoR1 binding when present at stoichiometric levels with respect to Rev$\operatorname{erb} \beta$. In stark contrast to those results, heme is required for coimmunoprecipitation of endogenous NCoR1 from HEK 293 cell extracts with Rev-erb $\beta$. Further, wild-type recombinant FLRev-erb $\beta$ co-precipitated with NCoR1, however a variant in which the His axial ligand is substituted with Phe $(\mathrm{H} 568 \mathrm{~F})$, which exhibits a micromolar $K_{\mathrm{d}}$ for heme binding, is incapable of interacting with NCoR1. Similar results were previously observed with Rev-erb $\alpha$ and the cognate $\mathrm{H} 602 \mathrm{~F}$ variant, indicating that heme is essential for the interaction of both Rev-erb isoforms with NCoR1 (102). Thus, we hypothesize that an unidentified cellular component present in soluble extracts promotes the heme-dependent NCoR1 recruitment to Rev-erbs. Numerous candidates are worth investigating, especially those proteins shown to modulate Rev-erb $\alpha$ and $\beta$ stability or repressor activity, including glycogen synthase kinase $3 \beta$, which phosphorylates Reverb $\alpha$ promoting its stability (101); Tip60, an acetylase, and histone deacetylase 1 (HDAC1) that regulate $\operatorname{Rev}-\operatorname{erb} \beta$ repressor activity by adding, or removing an acetyl group from an RXKK motif (90); and ZNHIT-1, a zinc-finger protein that interacts with Rev-erb $\beta$ at the apo-CIII promoter, inhibiting its repressor activity (89). Heme-dependent interaction between any of these proteins and Rev-erb has not been investigated (Fig. 4).

An alternative hypothesis to explain the missing link between heme binding and NCoR1 recruitment is that diatomic gaseous signaling molecules, primarily nitric oxide (NO) and $\mathrm{CO}$, could regulate Rev-erb $\alpha / \beta$ repressor activity. Both the truncated Rev-erb $\beta$ LBD and FLRev-erb $\beta$ bind CO with low nanomolar $K_{\mathrm{d}} \mathrm{s}$, but $\mathrm{CO}$ appears to have no effect on repressor 


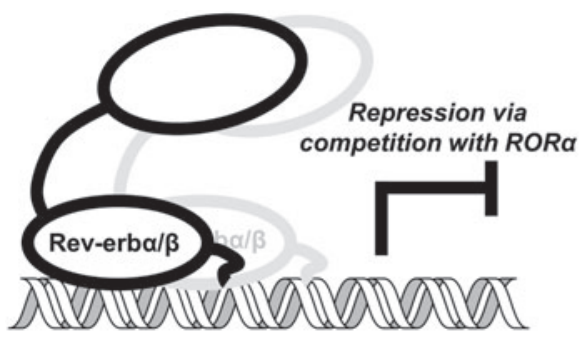

Rev-erba/ $\beta$ target gene promoter
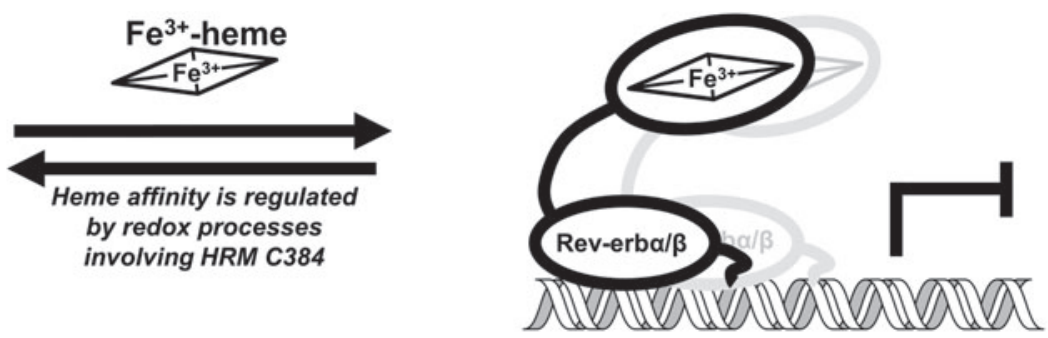

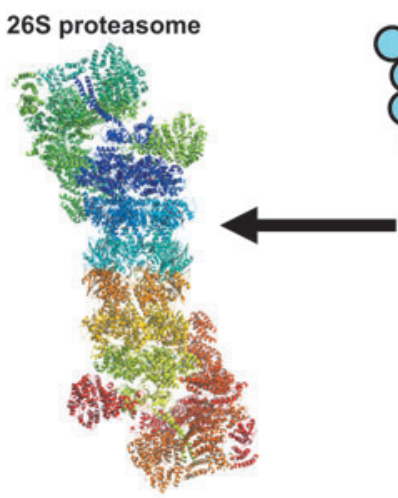
Additional transcriptional regulators bind to, and modulate Rev-erba/ $\beta$ repressor activity/stability
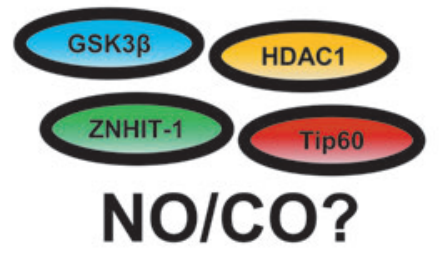

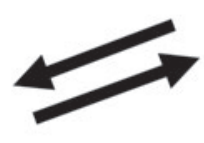

Rev-erba/ $\beta$ are degraded via E3-ligase/ubiquitin pathways; heme modestly promotes degradation of

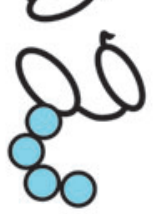

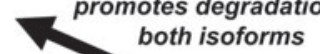

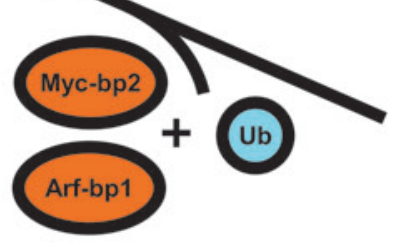

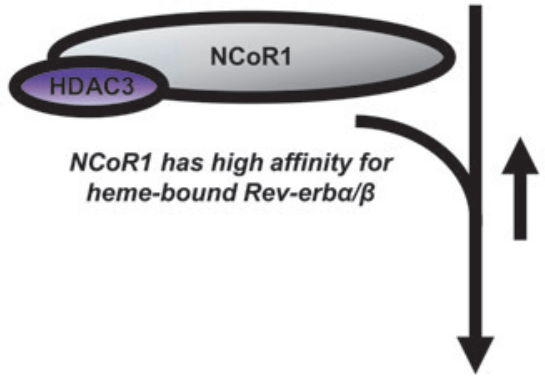

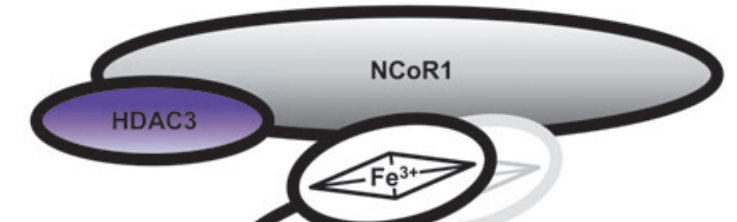

FIG. 4. Heme-dependent repression and degradation of Rev-erb $\alpha / \beta$. One mode of Rev-erb $\alpha / \beta$ repression is through competition with ROR $\alpha$ for binding to its response element (ROR-RE) within the promoters of target genes. Rev-erbs can bind as monomers and homodimers to Rev-REs, although recent studies suggest that they may also form heterodimers $(8,13,31)$. Although $\mathrm{Fe}^{3+}$-heme binds to Rev-erb $\beta$ with high affinity $\left(K_{\mathrm{d}} \leq 0.1 \mathrm{n} M\right)$, redox processes that cause dissociation of the $\mathrm{Fe}^{3+}$-heme axial thiolate ligand (including thiol-disulfide interconversion and $\mathrm{Fe}^{3+}$ - to $\mathrm{Fe}^{2+}$-heme reduction) cause $K_{\mathrm{d}}$ to increase to $\geq 14 \mathrm{n} M$ (11). Since the concentration of RH in the nucleus is $\leq 2.5 \mathrm{n} M(30)$, loss of the HRM heme axial thiolate would cause dissociation of heme. Coimmunoprecipitation studies show that the NCoR1-HDAC3 complex has a high affinity for heme-bound Rev-erb $\alpha / \beta$ (70, 102); once bound, the complex leads to target gene repression via histone deacetylation. Additional regulators of Rev-erb $\beta$ repressor activity have been identified, including Tip60, an acetyl transferase, HDAC1, a histone deacetylase, and ZNHIT-1, a zinc-finger containing protein; GSK3 $\beta$ has also been shown to regulate the stability of the $\alpha$-isoform (see main text for references); whether heme plays a role in regulating interactions of these proteins with Rev-erbs is unknown. Gaseous signaling molecules, NO and CO may also regulate the repressor function of Rev-erbs by binding to heme; however, additional studies are required to support this hypothesis. Although heme facilitates interaction of NCoR1 with Rev-erbs, it also appears to promote proteasomal degradation of both isoforms through a ubiquitin-dependent pathway involving E3-ligases Arf-bp1 and Myc-bp2. CO, carbon monoxide; HDAC1, histone deacetylase 1; NO, nitric oxide; RH, regulatory heme; ROR $\alpha$, RAR-related orphan receptor $\alpha$.

activity in a cellular system $(9,27,66)$. NO, on the other hand, has been shown to inhibit Rev-erb $\alpha / \beta$ repressor activity in cultured cells (66), but those results have yet to be validated in vivo, or the mechanistic details revealed. For example, does NO binding cause dissociation of NCoR1? What is the affinity of $\mathrm{Fe}^{2+}$-heme $\bullet \mathrm{Rev}$-erb $\alpha / \beta$ for $\mathrm{NO}$, and is that value consistent with the intracellular concentrations of NO? Does NO have secondary effects such as nitrosylation of Reverb zinc-finger thiolates as has been observed with other NRs (10)? In sum, additional studies are required to clarify the role, if any, of diatomic gases in Rev-erb regulation of target genes.
UV-vis spectrophotometric titrations revealed that $\mathrm{Fe}^{3+}$ and $\mathrm{Fe}^{2+}$-heme bind FLRev-erb $\beta$ with at least one order of magnitude higher affinity (low nanomolar $K_{\mathrm{d}} \mathrm{s}$ ) than those early estimates using ITC. Further, based on competition experiments, dissociation of $\mathrm{Fe}^{3+}$-heme from the FLRev$\operatorname{erb} \beta \bullet$ heme complex was too slow to allow rapid equilibration of Rev-erb $\beta$ with RH $\left(10^{-6} \mathrm{~s}^{-1}=<1\right.$ day $\left.^{-1}\right)$, negating its role as a sensor of intracellular $\mathrm{Fe}^{3+}$-heme (9). If so, does the HRM serve any regulatory function other than to bind heme and poise the receptor for interaction with NCoR1? In the next section, we discuss results suggesting that Rev-erbs may exploit the redox properties of the HRM cysteine thiolate and 
$\mathrm{Fe}^{3+}-/ \mathrm{Fe}^{2+}$-heme couple to regulate heme affinity and corepressor recruitment.

\section{Role of heme dissociation in redox signaling} by Rev-erb $\beta$

Early biophysical studies of Rev-erb $\beta$ described UV-vis, resonance Raman, EPR, and magnetic circular dichroism (MCD) spectra consistent with a low-spin 6-coordinate His/ Cys ligated $\mathrm{Fe}^{3+}$-heme, as observed in the crystal structure shown in Figure 3A (58). However, reduction by dithionite to $\mathrm{Fe}^{2+}$-heme leads to dissociation of the $\mathrm{C} 384$ axial thiolate and its replacement by an exchangeable neutral ligand (Fig. 5). Since the loop containing the HRM is largely disordered and is not present in the structure of the apoprotein, we assume
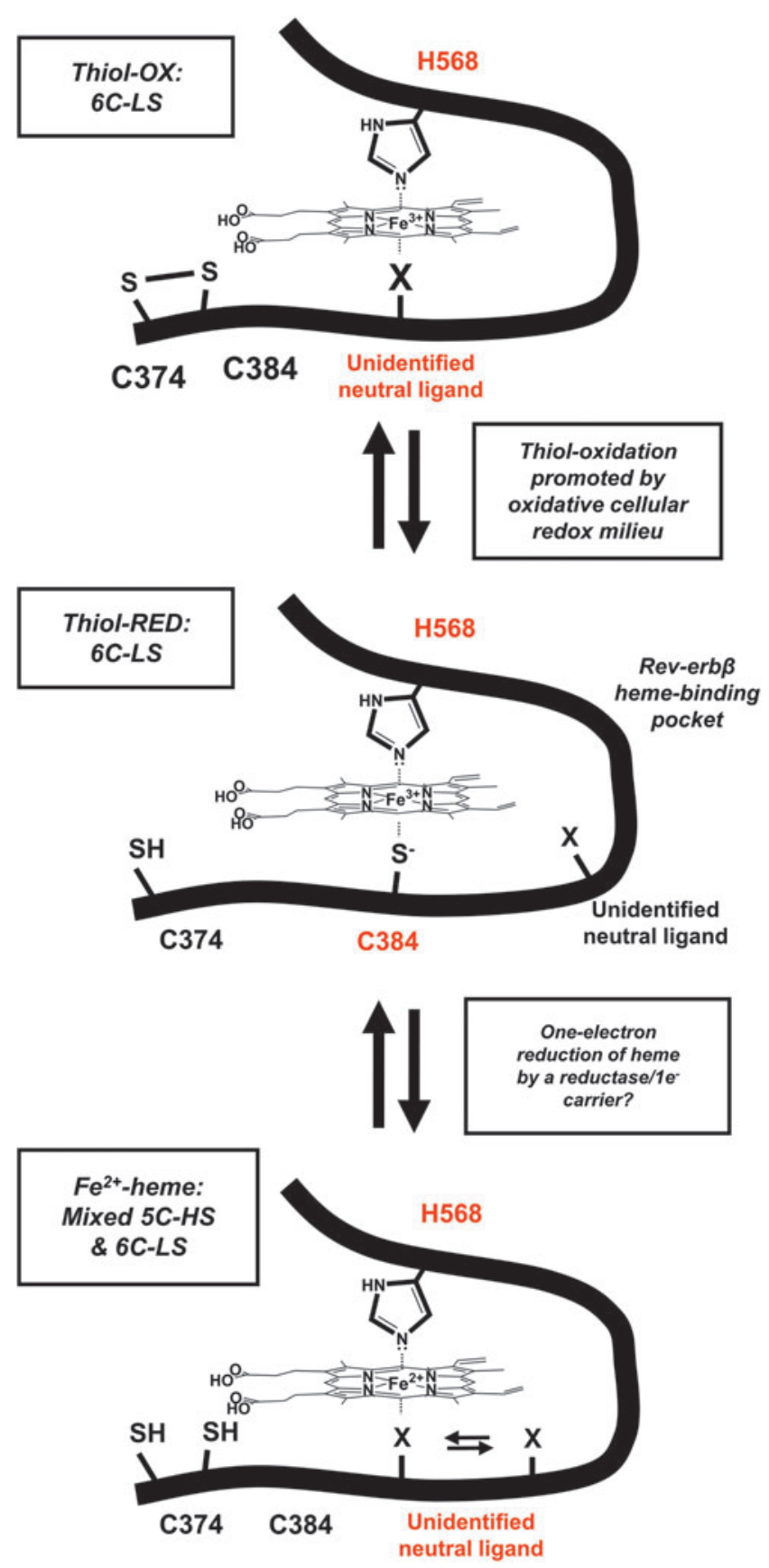

that dissociation of $\mathrm{C} 384$ from heme would result in significant conformational changes. UV-vis equilibrium titrations suggested that $\mathrm{Rev}-\mathrm{erb} \beta$ binds both $\mathrm{Fe}^{2+}$ - and $\mathrm{Fe}^{3+}$-heme with similar low nanomolar affinity $(9,27)$. However, as discussed later, most equilibrium techniques vastly underestimate heme affinities and $\mathrm{Fe}^{2+}$-heme may not remain bound under the limiting heme concentrations in the cell. Several important questions require investigation to determine whether $\mathrm{Fe}^{3+} /$ $\mathrm{Fe}^{2+}$-heme switching plays a role in regulating Rev-erb activity. For instance, what is the midpoint potential of the $\mathrm{Fe}^{3+}$ / $\mathrm{Fe}^{2+}$-heme $\bullet$ Rev-erb couple, and what is the redox state of heme bound to Rev-erbs in the cell? Is the $\mathrm{Fe}^{3+} / \mathrm{Fe}^{2+}$-heme switch sensitive to changes in intracellular redox poise? If it is, what one-electron carrier or reductase is responsible for mediating Rev-erb $\alpha / \beta$ reduction?

Another potential redox switch regulating $\operatorname{Rev}-\operatorname{erb} \beta$ repressor activity involves thiol-disulfide interconversion of the HRM cysteine. Under oxidizing conditions, C384 forms a disulfide bond with neighboring C374, causing an unidentified neutral ligand to assume the position of $\mathrm{C} 384$ in the $\mathrm{Fe}^{3+}$ -heme complex (Fig. 5) (27). The $K_{\mathrm{d}}$ of the thiol-oxidized protein for $\mathrm{Fe}^{3+}$-heme $(117 \mathrm{n} M)$ is approximately five-fold higher than that for the thiol-reduced form $(23 \mathrm{n} M)$, suggesting that thiol-disulfide interplay could regulate $\operatorname{Rev}-\operatorname{erb} \beta$ heme occupancy. Further, the switch occurs in Escherichia coli cells overproducing the Rev-erb $\beta$ LBD, which exhibit a whole-cell EPR spectrum consistent with that of a thiolreduced, six-coordinate low-spin $\mathrm{Fe}^{3+}$-heme; then, treatment of cells with the thiol oxidant, diamide, yields a spectrum indicative of a mixture of thiol-reduced/thiol-oxidized species. These data support the hypothesis that the $\operatorname{Rev}-\operatorname{erb} \beta$ HRM is redox active and that the disulfide bond forms under oxidizing conditions. Future work should focus on whether the $\operatorname{Rev}-\operatorname{erb} \beta$ thiol-disulfide rheostat occurs in mammalian cells in the context of the full-length protein and whether it interfaces with cellular redox buffers, for example, the glutathione:glutathione disulfide and dehydroascorbic acid:ascorbic

FIG. 5. Rev-erb $\beta$ undergoes redox-mediated heme ligand switching. The thiol-reduced form of the Rev-erb $\beta$ LBD (thiol-RED; C374 and C384 exist as thiols/thiolates) binds $\mathrm{Fe}^{3+}$-heme in 6C-LS complex with $\mathrm{H} 568$ and $\mathrm{C} 384$ axial ligands and a $K_{\mathrm{d}}$ of $\sim 100 \mathrm{p} M$. Under oxidizing conditions, C384 forms a disulfide with neighboring C374 (thiol$\mathrm{OX}$ ), leading to a 6C-LS system where an unidentified neutral ligand assumes the position once occupied by the thiolate. Thiol-OX has a $K_{\mathrm{d}}$ for $\mathrm{Fe}^{3+}$-heme of $\geq 14 \mathrm{n} M$, well above the nuclear RH level of $\leq 2.5 \mathrm{n} M$, suggesting that thiol-OX would exist as an apoprotein in the nucleus. Our working hypothesis is that C374-C384 thiol-disulfide interconversion is in equilibrium with the GSH:GSSG or cysteine:cystine couples and reflects the redox poise of the nucleus. Similarly, the oneelectron reduction of $\mathrm{Fe}^{3+}$ - to $\mathrm{Fe}^{2+}$-heme is accompanied by dissociation of the HRM heme axial thiolate, leading to a mixed 5C-HS/6C-LS system where an unidentified neutral ligand (presumably the same ligand involved in the thiol$\mathrm{RED} / \mathrm{OX}$ ligand switch) is loosely associated with heme. Although it is unclear what heme redox state is relevant to $\operatorname{Rev}-\operatorname{erb} \beta$ in the cell, it is intriguing to consider one-electron reductants that could interface with $\operatorname{Rev}-\operatorname{erb} \beta$, such as ferredoxins or cytochrome $\mathrm{P} 450$ reductase, although nuclear localization of the reductant is presumably required. 5C-HS, five-coordinate high spin; 6C-LS, six-coordinate low-spin. 
acid systems that are under circadian control (92). Because Rev-erb $\alpha / \beta$ protein levels are tightly regulated by the transcription/translation feedback cycle of the molecular clock, redox regulation might represent an additional mechanism of controlling Rev-erb repressor activity.

\section{Transient kinetic experiments support the hypothesis that the HRM in Rev-erb $\beta$ is a redox sensor}

A caveat of our early estimates of $K_{\mathrm{d}}$ for the $\mathrm{Fe}^{3+} / \mathrm{Fe}^{2+}$. heme complexes with FLRev-erb $\beta$ and thiol-reduced/ oxidized LBDs was the use of equilibrium titrations. Because $K_{\mathrm{d}} \mathrm{s}$ for these complexes are in the low nanomolar range, UVvis spectrophotometric titrations performed with micromolar concentrations of heme and protein yield typical, "dog-leg", curves that sharply saturate at 1:1 stoichiometry of heme and protein. Under such conditions, the concentration of free ligand cannot be assumed to equal the total concentration since most of the ligand is protein bound below a 1:1 ratio. The quadratic equation accounts for the concentrations of total versus free heme in such titrations but is limited in that the accuracy of the $K_{\mathrm{d}}$ is dependent on the sharpness of the curve; below a 10 nanomolar $K_{\mathrm{d}}$, the standard error of the fit becomes rather large. To circumvent these issues, we used a kinetic approach, analyzing individual rate constants for the association $\left(k_{\text {on }}\right)$ and dissociation $\left(k_{\text {off }}\right)$ of heme and Rev$\operatorname{erb} \beta$, ultimately establishing accurate $K_{\mathrm{d}} \mathrm{s}$ using the basic expression, $K_{\mathrm{d}}=k_{\mathrm{off}} / k_{\mathrm{on}}$. As detailed in our recent manuscript (11), we utilized a unique buffer system containing caffeine, which has been shown to dissociate heme dimers and oligomers that usually complicate measurements of $k_{\text {on }}$ using stopped-flow techniques because of their first-order, ratelimiting dissociation.

Heme association to Rev-erb $\beta$ was complex and proceeded through several different kinetic steps. However, the initial binding phase, which made up $>50 \%$ of total amplitude change, was hyperbolic with respect to protein concentration, indicative of a two-step binding mechanism (81). Similar hyperbolic dependence of $k_{\mathrm{obs}}$ on protein concentration has been observed in other heme:hemoprotein systems, suggesting that they have similar mechanisms of heme association $(20,54,64)$. Interestingly, the $k_{\text {on }}$ values for $\mathrm{Fe}^{3+}$-heme binding to wild-type protein, a C384A variant lacking the HRM cysteine thiolate, and the thiol-oxidized form were between $3.6 \times 10^{5} M^{-1} \mathrm{~s}^{-1}$ and $4.1 \times 10^{5} M^{-1} \mathrm{~s}^{-1}$, indicating that loss of the axial thiolate has a negligible influence on heme binding. $\mathrm{Fe}^{2+}$-heme association, however, proceeded with a second-order rate constant of $k_{\text {on }}=2.7 \times 10^{6} M^{-1} \mathrm{~s}^{-1}$, demonstrating that the heme redox state is an important determinant of $k_{\text {on }}$.

The measurement of $k_{\text {on }}$ was relatively straightforward, whereas heme dissociation was biphasic, that is, affording two $k_{\text {off }}$ values. For these experiments, one follows heme dissociation from Rev-erb $\beta$ by monitoring formation of the complex between heme and the H64Y/V68F myoglobin variant, which exhibits a unique UV-vis spectrum. For wildtype Rev-erb $\beta$, off-rates were between $10^{-4}-10^{-5} \mathrm{~s}^{-1}$, with a $K_{\mathrm{d}}$ range of 104-639 $\mathrm{p} M$; the slow kinetic phase predominated and made up $>80 \%$ of the total amplitude, indicating that most of the bound heme dissociates with a $K_{\mathrm{d}}$ of $\sim 100 \mathrm{p} M$. In contrast, the $\mathrm{Fe}^{3+}$-heme off-rates from thioloxidized and C384A proteins were between $10^{-2}$ and $10^{-3} \mathrm{~s}^{-1}$, giving $K_{\mathrm{d}}$ ranges of $14-50 \mathrm{n} M$ and $4-32 \mathrm{n} M$, respectively. Further, the $k_{\text {off }}$ values of $\mathrm{Fe}^{2+}$-heme from wild-type protein were $1.4 \mathrm{~s}^{-1}-6.5 \times 10^{-2} \mathrm{~s}^{-1}$, yielding a $K_{\mathrm{d}}$ range of 24$519 \mathrm{n} M$. Thus, dissociation of the axial thiolate via either redox process (oxidation of the HRM thiolate to a disulfide or heme reduction) significantly lowers Rev-erb $\beta$ heme affinity. In other words, Rev-erb $\beta$ exhibits features of a redox sensor rather than a direct heme sensor. This hypothesis gains momentum given coimmunoprecipitation results demonstrating that the C384A variant of FLRev-erb $\beta$ loses $>70 \%$ NCoR 1 binding capacity with respect to wild-type protein, corroborating the importance of the HRM cysteine in stabilizing both heme and NCoR1 interactions.

These redox sensor-related results take on an even greater impact in the context with recent work by Reddi and colleagues describing the accurate determination of intracellular RH levels in Saccharomyces cerevisiae (30). In that study, fluorescent heme sensors were targeted to different subcellular organelles and RH levels were determined by using elegant normalization techniques that defined fluorescence emission ratios (with respect to an internal fluorescence standard) of the sensors in heme-free and heme-replete conditions. RH in the cytosol was found to be $20-40 \mathrm{n} M$, whereas heme levels are kept at a minimum $(<2.5 \mathrm{n} M)$ in the mitochondria and nucleus. RH in the nucleus and mitochondria is likely maintained at these extremely low levels to limit the amount of free heme available to participate in Fenton reactions, leading to damaged DNA or respiratory chain elements. A complicating factor is that the heme sensor employed is insensitive to $\mathrm{Fe}^{3+}$-heme at the low concentrations present in the cell; thus, the aforementioned values are reflective of the $\mathrm{Fe}^{2+}$-heme $\mathrm{RH}$ pool, although $\mathrm{Fe}^{3+}$-heme $\mathrm{RH}$ is also likely to exist due to varying ligand conformations with glutathione or protein side chains in the cellular milieu. In any case, those values provided in the aforementioned study lay the groundwork for discussions on the likelihood of heme:protein interactions with an $\mathrm{RH}$ pool in the low nanomolar range. Since the majority of the thiol-reduced, wildtype $\mathrm{Rev}-\mathrm{erb} \beta$ population binds $\mathrm{Fe}^{3+}$-heme with a $K_{\mathrm{d}}$ of $0.1 \mathrm{n} M$, it would predominantly exist as holoprotein with $<2.5 \mathrm{n} M \mathrm{RH}$ in the nucleus. However, thiol oxidation or heme reduction drives the $K_{\mathrm{d}}$ above $14 \mathrm{n} M$. Because these values lie on the upper end of the RH estimation, $\mathrm{Rev}-\operatorname{erb} \beta$ may exist as an apoprotein under those conditions. Another hypothesis is that Rev-erbs might bind $\mathrm{Fe}^{2+}$-heme after being translated in the cytosol, with heme then oxidizing to $\mathrm{Fe}^{3+}$-heme to "lock in" a particular conformation of the protein. Regardless of this, the initial estimates of Rev-erb $\alpha / \beta$ affinity of $0.35-$ $3.52 \mu M$ with ITC are problematic in that they suggest the protein would exist within the cell in the apo form exclusively $(59,70)$. Our results underscore the importance of using highly sensitive spectroscopic and kinetic studies to investigate the molecular mechanism of heme-dependent NCoR1 recruitment, and the possibility of Rev-erbs acting as redox sensors either through the $\mathrm{Fe}^{3+} / \mathrm{Fe}^{2+}$-heme or the thiol-disulfide couple (11).

\section{Heme Oxygenase-2 \\ $\mathrm{HO} 2$ is an HRM-containing protein}

A variety of mechanisms are involved in the regulation of heme homeostasis to ensure that heme levels are maintained 
at concentrations that are high enough for cellular processes but low enough to avoid the cytotoxic effects of heme. One such mechanism involves heme degradation, a pathway in which heme is converted to biliverdin, and biliverdin is, subsequently, converted to the more readily excreted product bilirubin (55). The first step is rate limiting and is catalyzed by $\mathrm{HO}$, the only enzyme in mammals known to degrade heme.

$\mathrm{HO} 2$, one of the two major isoforms of HO identified in mammals, contains three HRMs (Fig. 1). One HRM, centered at Cys127-Pro128 in human HO2, is located in the $\alpha$-helical catalytic core region, consisting of residues 28-248 where heme binds and undergoes conversion to biliverdin. The other two HRMs, centered at Cys265-Pro266 and Cys282Pro283, are located in an unstructured region of the protein between the catalytic core and the membrane-spanning region that tethers the protein to the endoplasmic reticulum. HO2 was among the proteins first identified as having an HRM (105), and it was immediately thereafter noted that the presence of $\mathrm{HRMs}$ in $\mathrm{HO} 2$ distinguished it from $\mathrm{HO} 1$, which contains no cysteines (60). HO1 is an inducible protein expressed in most tissues but with particularly high levels in the liver and spleen, whereas HO2 is constitutively expressed and has been primarily identified in the brain and testes (55). However, the two proteins convert heme to biliverdin with similar catalytic efficiencies (56) and share a high level of homology (55\% identical and 76\% similar for the human proteins). A comparison of the structures of $\mathrm{HO} 2$ and $\mathrm{HO} 1$ illustrates how similar the two proteins are in the catalytic core region, consisting of residues 1-230 in human $\mathrm{HO1}(4,78)$. However, the $\mathrm{HO} 2$ and $\mathrm{HO} 1$ sequences diverge significantly between the catalytic core and the membrane-spanning region where the HRMs of $\mathrm{HO} 2$ are located, a region for which there is little structural information. As the HRMs appear to be the major difference between the two proteins, attention has been given to the heme-binding properties and the function of the HRMs of HO2 in an effort to understand why nature has selected a new form of $\mathrm{HO}$ that catalyzes the same reaction with a similar catalytic efficiency as the ancient form (HO1).

\section{Heme binding to the HRMs of $\mathrm{HO} 2$}

To infer that any differences between $\mathrm{HO} 2$ and $\mathrm{HO} 1$ are linked to the presence of HRMs in $\mathrm{HO} 2$, heme binding to the HRMs needed to be confirmed. An initial study of rat $\mathrm{HO} 2$ (60) demonstrated that adding heme to a 10 -mer peptide spanning one of the HRMs (Val-Arg-Lys-Cys 264 -Pro-PheTyr-Ala-Ala-Gln) results in a dramatic color change, suggesting heme ligation. A more subtle color change was observed for a peptide spanning the other C-terminal HRM (Gly-Ser-Asn$\mathrm{Cys}_{281}$-Pro-Phe-Arg-Thr-Ala-Met). Further, subtle differences in the absorbance spectra of a Cys264Ala/Cys281Ala variant of rat $\mathrm{HO} 2$ as compared with the wild-type led to the hypothesis that the wild-type was binding $\sim 2$ more equivalents of heme per monomer of protein than the variant, suggesting that the HRMs were involved in binding heme independently of heme binding to the catalytic core (60). The results were slightly ambiguous but enough to pique the curiosity of others.

A significant finding in the further characterization of the HRMs was the discovery of a disulfide bond involving the cysteines in the HRMs of the soluble form of human HO2 $\left(\mathrm{HO} 2_{\text {sol }}\right)$, which spans residues 1-288, thus eliminating residues 289-316, which form the membrane-spanning region. Cys265 and Cys282 were shown to form a disulfide bond by the 5,5'-dithiobis(nitrobenzoic acid) (DTNB) assay and by monitoring alkylation of the cysteine residues using mass spectrometry (99). A later study using ${ }^{13} \mathrm{C}$-Cys-labeled $\mathrm{HO}_{2}$ sol and two-dimensional NMR also confirmed disulfide bond formation (86). Further, through thiol trapping experiments using the isotope-coded affinity tag technique (53), the thiols were shown to be $60-70 \%$ reduced in vivo under normal growth conditions (98). The dithiol/disulfide ratio also changed to reflect changes in the cellular redox state, with $81-87 \%$ of thiols reduced under reducing conditions and $86-89 \%$ of thiols in the disulfide state under oxidizing conditions. The midpoint potential for the thiol/disulfide conversion, measured by thiol trapping and fluorescence trapping, was calculated to be $-200 \mathrm{mV}$, which is near the ambient cellular redox potential (71). Thus, the thiol/disulfide conversion appears to be physiologically relevant and to link $\mathrm{HO} 2$ to the cellular redox state.

The added significance of the thiol/disulfide conversion in $\mathrm{HO} 2$ is that a disulfide bond necessarily limits the ability of Cys265 and Cys282 to coordinate $\mathrm{Fe}^{3+}$-heme. Indeed, no thiol coordination of $\mathrm{Fe}^{3+}$-heme was observed with fully oxidized (disulfide state) as-purified $\mathrm{HO}_{\text {sol }}$ (99), and its spectral features were identical to those of a truncated form of $\mathrm{HO} 2$ ( $\mathrm{HO} 2_{\text {core }}$ ), which spans residues 1-248 and lacks the Cterminal HRMs $(20,99)$. Titration of oxidized $\mathrm{HO} 2_{\text {sol }}$ $\left(\mathrm{HO} 2_{\text {sol }} \mathrm{O}^{\circ}\right)$ or $\mathrm{HO} 2_{\text {core }}$ with $\mathrm{Fe}^{3+}$-heme resulted in an increase at $406 \mathrm{~nm}$ that saturated at $1: 1$ protein to $\mathrm{Fe}^{3+}$-heme and an EPR signal (signal X) with $g$ values at 2.87, 2.26, and 1.99 (Fig. 6). These results are consistent with His/aquo axial ligation to the $\mathrm{Fe}^{3+}$-heme in the catalytic core, including the imidazole of a conserved His (His45 in human HO2) and a solvent water, which interacts with a glycine-rich helix (4).

Surprisingly, on reduction of the disulfide bond of $\mathrm{HO} 2$ and subsequent incubation with $\mathrm{Fe}^{3+}$-heme, the EPR spectrum of $\mathrm{HO} 2_{\text {sol }} \mathrm{R}$ (reduced $\mathrm{HO} 2_{\text {sol }}$ ) included both signal $\mathbf{X}$ and a second signal (signal Y) with $g$ values at 2.41, 2.26, and 1.91 , which are characteristic of six-coordinate $\mathrm{Fe}^{3+}$-heme with Cys/His ligation (20, 99) (Fig. 6). Thiol ligation had never been observed for any form of $\mathrm{HO}$ and is a feature characteristic of an entirely different class of hemoproteins, for example, cytochrome $\mathrm{P}_{450}(26)$ and some regulatory hemoproteins $(37,71)$. Various results in different groups indicated that only one heme was bound per HO2 monomer $(86,99)$. Thus, to account for signal Y, a "fishhook" mechanism was initially proposed in which a Cys from an HRM (likely Cys265 based on mutational studies) displaces an axial ligand at $\mathrm{Fe}^{3+}$-heme bound to the catalytic site on reduction of the disulfide bond, resulting in His45/Cys265 ligation of $\mathrm{Fe}^{3+}$-heme (99). However, problems with this proposal began to mount, favoring a model (Fig. 6D) in which $\mathrm{Fe}^{3+}$-heme binding to Cys residues in the HRMs is independent of binding to His45 at the catalytic core (20). For example, signal $\mathbf{Y}$ was observed in forms of $\mathrm{HO} 2$ in which His45 is not available to ligate heme, as in, the His45Ala variant of $\mathrm{HO}_{2}{ }_{\text {sol }}^{\mathrm{R}}$ and $\mathrm{HO} 2$ in the disulfide bond-reduced form, spanning residues $213-288\left(\mathrm{HO} 2_{\text {tail }}{ }^{\mathrm{R}}\right)$, which lacks the heme-binding site in the catalytic core (20). Rather, ${ }^{14} \mathrm{~N}$ and ${ }^{15} \mathrm{~N}$ Davies ENDOR spectroscopic experiments showed that 

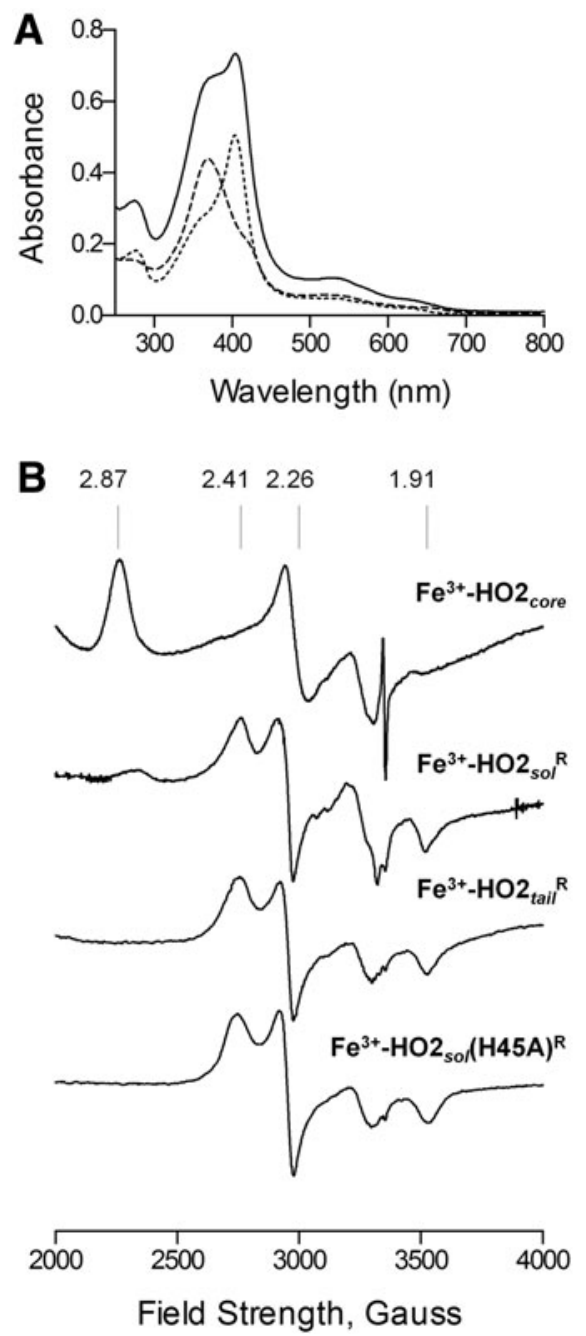

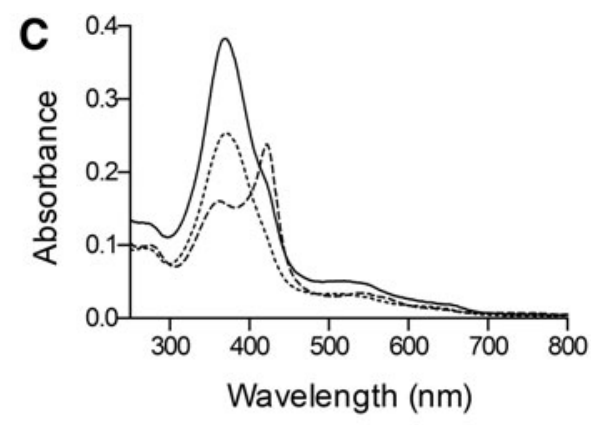

D

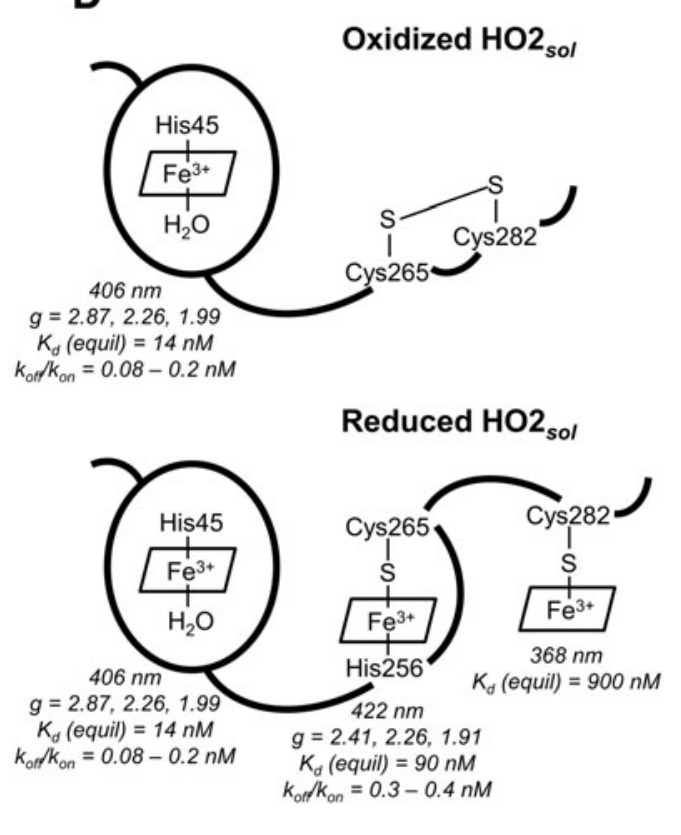

FIG. 6. Spectral characterization of $\mathbf{H O 2}$ in the $\mathbf{F e}^{\mathbf{3 +}}$-heme-bound forms. (A) Absorbance spectra of $5 \mu M \mathrm{Fe}^{3+}-$ hemebound forms of $\mathrm{HO} 2_{\text {core }}(\cdots), \mathrm{HO} 2_{\text {tail }}{ }^{\mathrm{R}}(---)$, and $\mathrm{HO} 2_{\text {sol }}^{\mathrm{R}}(-)$ in $50 \mathrm{mM}$ Tris (pH 8.0) and $50 \mathrm{mM} \mathrm{KCl}$ at $20^{\circ} \mathrm{C}$. (B) EPR spectra of the $\mathrm{Fe}^{3+}$-heme-bound forms of $\mathrm{HO} 2_{\text {core }}, \mathrm{HO} 2_{\text {sol }}, \mathrm{HO} 2_{\text {tail }}$, and the His45Ala variant of $\mathrm{HO} 2_{\text {sol }}$. The $g$ values are indicated above the spectra. (C) Absorbance spectra of $5 \mu M \mathrm{Fe}^{3+}$-heme-bound forms of $\mathrm{HO} 2_{\text {tail }}^{\mathrm{R}}(-), \mathrm{HO} 2_{\text {tail }}(\mathrm{C} 282 \mathrm{~A})^{\mathrm{R}}(---)$, and $\mathrm{HO} 2_{\text {tail }}(\mathrm{C} 265 \mathrm{~A})^{\mathrm{R}}(\cdots)$ in $50 \mathrm{mM}$ Tris $(\mathrm{pH} 8.0)$ and $50 \mathrm{mM} \mathrm{KCl}$ at $20^{\circ} \mathrm{C}$. (D) A model of heme binding to the oxidized form of $\mathrm{HO}_{2 o l}$, which has a single heme-binding site due to the participation of Cys265 and Cys282 in a disulfide bond, and the reduced form of $\mathrm{HO}_{\text {sol }}$, which has three heme-binding sites. Below each heme-binding site are the characteristics of that site, including the maximum absorbance, the $g$-values, the $K_{\mathrm{d}}$ values obtained by equilibrium titrations $\left[K_{\mathrm{d}}\left(\right.\right.$ equil)], and the $\mathrm{k}_{\mathrm{off}} / \mathrm{k}_{\mathrm{on}}$ values obtained by kinetic measurements. The figures in (A-C) are reprinted (adapted) with permission from Fleischhacker et al. (20). Copyright (2015) American Chemical Society. EPR, electron paramagnetic resonance; $\mathrm{HO} 2_{\text {core }}, \mathrm{HO} 2$ spanning residues 1-248; $\mathrm{HO}_{2}{ }^{\mathrm{R}}, \mathrm{HO} 2$ in the disulfide bond-reduced form; $\mathrm{HO} 2_{\text {sol }}, \mathrm{HO} 2$ spanning residues $1-288 ; \mathrm{HO} 2_{\text {tail }}, \mathrm{HO} 2 \mathrm{spanning}$ residues $213-288$.

His256 is an axial ligand to the heme giving rise to signal $\mathbf{Y}$ (20). Indeed, the absorbance spectra of the $\mathrm{Fe}^{3+}$-heme-bound forms of $\mathrm{HO} 2_{\text {tail }} \mathrm{R}^{\mathrm{B}}$ and $\mathrm{HO} 2_{\text {core }}$ could account for all of the features observed for $\mathrm{HO} 2_{\text {sol }}^{\mathrm{R}}$ (Fig. 6A, B); for example, the absorbance band at $422 \mathrm{~nm}$ is typical for Cys/His ligated $\mathrm{Fe}^{3+}$-heme $(37,58,62)$ and could be assigned to Cys265/ His256 ligation (as well as accounting for the shoulder in the spectrum of $\mathrm{HO} 2_{\text {sol }}^{\mathrm{R}}$ ), whereas the broad band at $368 \mathrm{~nm}$ could be assigned to the Cys282 site $(20,105)$. Quantification of $\mathrm{Fe}^{3+}$-heme bound to the various $\mathrm{HO} 2$ forms by pyridine hemochrome assay (20) also demonstrated that the thiolreduced $\mathrm{HO} 2$ has three independent $\mathrm{Fe}^{3+}$-heme-binding sites.

Various spectroscopic techniques were used to probe for the thiol-coordinated $\mathrm{Fe}^{3+}$-heme in $\mathrm{HO} 2$. MCD spectra of
$\mathrm{Fe}^{3+}$-heme-bound human $\mathrm{HO} 2$ and the Cys variants suggested that a six-coordinate, Cys265-ligated $\mathrm{Fe}^{3+}$-heme is formed as a minor species on reduction of the disulfide bond (22); Fe K-edge EXAFS and XAS data supported thiol coordination by both Cys265 and Cys282, although Cys265 appeared to bind with a somewhat higher affinity than Cys282 to the $\mathrm{Fe}^{3+}$ center (2); and ${ }^{1} \mathrm{H}$ and ${ }^{13} \mathrm{C}$ ENDOR experiments using reduced, $\mathrm{Fe}^{3+}$-heme-bound $\mathrm{HO} 2$ that had been ${ }^{2} \mathrm{H}-\mathrm{Cys}$ or ${ }^{13} \mathrm{C}-\mathrm{Cys}$ labeled conclusively demonstrated $\mathrm{Fe}^{3+}$-heme coordination at the HRMs (2). Thus, collectively these various lines of enquiry unambiguously showed that the reduced state of HO2 contains three hemes (Fig. 6D): one at the catalytic core (His45/aquo) and two additional heme-binding sites at the Cterminal HRMs: Cys265/His256 and Cys282. Regardless of 
this, one study proposed that the HRMs of $\mathrm{HO} 2$ do not stably coordinate to $\mathrm{Fe}^{3+}$-heme (86); however, in that study involving equilibrium titrations, $\mathrm{Fe}^{3+}$-heme was added to $\mathrm{HO} 2$ in the presence of excess tris(2-carboxyethyl)phosphine, and phosphines are reasonably strong $\mathrm{Fe}^{3+}$-heme ligands $(57,75,83)$.

\section{Kinetics of heme binding to $\mathrm{HO} 2$}

Spectral data suggested that the three binding sites of $\mathrm{HO} 2$ had varying affinities for $\mathrm{Fe}^{3+}$-heme. At less than saturating concentrations of $\mathrm{Fe}^{3+}$-heme, the spectra were dominated by features associated with $\mathrm{Fe}^{3+}$-heme binding at the His45/aquo site, suggesting that the catalytic core had a higher affinity for $\mathrm{Fe}^{3+}$-heme than the HRMs. Further, Fe K-edge EXAFS and XANES data suggested that Cys265 had a higher affinity for $\mathrm{Fe}^{3+}$-heme than Cys282 (2). However, $\mathrm{Fe}^{3+}$-heme $K_{\mathrm{d}}$ values were difficult to ascertain from equilibrium titrations of $\mathrm{HO} 2_{\text {sol }}^{\mathrm{R}}$ due to the complexity of the UV-vis spectra. Thus, equilibrium titrations of the truncated forms of $\mathrm{HO} 2$ were performed and revealed $K_{\mathrm{d}}$ values of $14 \mathrm{n} M$ for $\mathrm{HO}_{2}$ core ( $\mathrm{Fe}^{3+}$-heme binding to the His45/aquo site), $90 \mathrm{n} M$ for

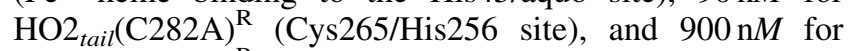

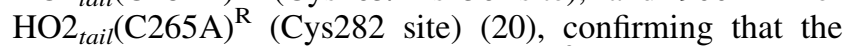
three sites have varying affinities for $\mathrm{Fe}^{3+}$-heme.

However, as discussed earlier for $\operatorname{Rev}-\operatorname{erb} \beta$, equilibrium titrations may not give the most accurate $K_{\mathrm{d}}$ values. Instead, individual rate constants for the association $\left(k_{\mathrm{on}}\right)$ and dissociation $\left(k_{\text {off }}\right)$ of $\mathrm{Fe}^{3+}$-heme provided a more detailed view of binding. Further, this kinetic approach permitted the observation of $\mathrm{Fe}^{3+}$-heme binding to some of the sites in $\mathrm{HO} 2_{\text {sol }} \mathrm{R}$. The rate constants were very similar for the sites in the truncated proteins as the comparable site in $\mathrm{HO}_{\text {sol }} \mathrm{R}$, indicating that the truncated proteins are good models for the fulllength protein. Calculation of $K_{\mathrm{d}}$ values using the simple equation $K_{\mathrm{d}}=k_{\text {off }} / k_{\text {on }}$ revealed $K_{\mathrm{d}}$ values of $0.08-0.2 \mathrm{n} M$ for $\mathrm{Fe}^{3+}$-heme binding to the His45/aquo site and $0.3-0.4 \mathrm{n} M$ for $\mathrm{Fe}^{3+}$-heme binding to the Cys265/His256 site (20). The $k_{\text {on }}$ value could not be determined for $\mathrm{Fe}^{3+}$-heme binding to the Cys282 site, but estimates would suggest a value of $\sim 1 \mathrm{n} M$. Values obtained by kinetic measurements follow the same trend as equilibrium titrations, that is, the His45/aquo site has a higher affinity than Cys265/His256, which, in turn, has a higher affinity than Cys282. However, the lower $K_{\mathrm{d}}$ values are on par with RH levels in the cell, in contrast to the values obtained by equilibrium titrations that would have suggested that the HRMs only bind $\mathrm{Fe}^{3+}$-heme under conditions in which heme levels were elevated. Therefore, the redox state of the cell, by influencing the thiol/disfulfide conversion of Cys265 and Cys282, appears to be more relevant to $\mathrm{Fe}^{3+}$ -heme binding to the HRMs of $\mathrm{HO} 2$ than previously thought, suggesting that the HRMs function as redox sensors.

\section{Functional significance of HRMs in $\mathrm{HO} 2$}

HRMs appear to place $\mathrm{HO} 2$ in a unique position at which the redox state of the cell and regulation of heme and iron homeostasis intersect. However, the exact nature of their function remains unclear. Repeated experiments have demonstrated that the steady-state activity of $\mathrm{HO} 2$ is not affected by substitution of any of the Cys to Ala or by exclusion of the cysteine residues by truncation of the protein $(16,20,60,99)$. A more detailed investigation of heme hydroxylation, the initial steps in heme degradation, by $\mathrm{HO} 2$ using a combina- tion of radiolytic cryoreduction/annealing with UV-vis and EPR spectroscopy demonstrates that there is no involvement of the HRMs in the catalytic cycle of HO2 (16). In addition, the HRMs can bind but not oxidize heme as no steady-state activity was observed with $\mathrm{HO}_{\text {tail }}{ }^{\mathrm{R}}$ (16). $\mathrm{HO} 2$ and $\mathrm{HO} 1$ also appear to bind cytochrome $\mathrm{P} 450$ reductase, which provides electrons for the HO reaction, with the same corresponding residues (80), further suggesting that the degradation of heme proceeds in the catalytic core independently of the HRMs. HRMs are also not involved in the specific activation of $\mathrm{HO} 2$ by menadione analogs or its specific inhibition by clemizole analogs (87) nor do they participate in binding of the heme mimic Zn(II) PPIX, an HO inhibitor (36). Thus, further investigation is needed to detail the functional significance of heme binding to HRMs in a redox-regulated manner.

\section{Conclusions and Future Directions}

Here, we have highlighted $\mathrm{HO} 2$ and $\mathrm{Rev}-\operatorname{erb} \beta$ to illustrate the similarities and differences between two hemoproteins that both contain HRMs. HRMs of both proteins appear to act as redox sensors in that the participation of the HRM cysteine(s) in a thiol/disulfide switch alters affinity for heme. Therefore, future studies of HRM-containing proteins should include experiments that probe for disulfide bonds and/or differences in heme binding under oxidizing and reducing conditions. HRMs acting as redox sensors may be applicable to other HRM-containing proteins as many contain multiple HRMs and/or other cysteine residues. Further, the affinity for heme at the HRMs, based on the kinetic approach used for $\mathrm{HO} 2$ and $\operatorname{Rev}-\mathrm{erb} \beta$, may be lower than previously proposed, suggesting that the functional significance of the HRMs may be greater than expected. The survey of HRMcontaining proteins (see the Introduction section and Fig. 1) indicates that HRMs play a role in regulating protein stability in a significant number of proteins, many of which are involved in regulating circadian rhythm and metabolic pathways (Rev-erbs, p53, and Per2), suggesting that it may be advisable to probe more HRMs for this function. Thus, the study of HRMs, in general, is a growing field with many interesting questions yet to be answered.

\section{Acknowledgments}

This work has been funded by NIH (R21HL089837, R01GM123513, and R01-HL102662A) to SWR, F32HL114150 to ELC and by the University of Michigan Biomedical Research Council (to SWR).

\section{References}

1. Akashi M and Takumi T. The orphan nuclear receptor $\mathrm{ROR} \alpha$ regulates circadian transcription of the mammalian core-clock Bmall. Nat Struct Mol Biol 12: 441-448, 2005.

2. Bagai I, Sarangi R, Fleischhacker AS, Sharma A, Hoffman BM, Zuiderweg ERP, and Ragsdale SW. Spectroscopic studies reveal that the heme regulatory motifs of heme oxygenase- 2 are dynamically disordered and exhibit redox-dependent interaction with heme. Biochemistry 54 : 2693-2708, 2015.

3. Barr I, Smith AT, Senturia R, Chen YQ, Scheidemantle BD, Burstyn JN, and Guo F. DiGeorge critical region 8 (DGCR8) is a double-cysteine-ligated heme protein. $J$ Biol Chem 286: 16716-16725, 2011. 
4. Bianchetti CM, Yi L, Ragsdale SW, and Phillips GN, Jr. Comparison of apo- and heme-bound crystal structures of a truncated human heme oxygenase-2. J Biol Chem 282: 37624-37631, 2007.

5. Bohle DS, Dodd EL, Pinter TBJ, and Stillman MJ. Soluble diamagnetic model for malaria pigment: coordination chemistry of gallium(III)protoporphyrin-IX. Inorg Chem 51: 10747-10761, 2012.

6. Brewitz HH, Kühl T, Goradia N, Galler K, Popp J, Neugebauer U, Ohlenschlager O, and Imhof D. Role of the chemical environment beyond the coordination site: structural insight into Fe-III protoporphyrin binding to cysteine-based heme-regulatory protein motifs. Chembiochem 16: 2216-2224, 2015.

7. This reference has been deleted.

8. Bugge A, Feng D, Everett LJ, Briggs ER, Mullican SE, Wang F, Jager J, and Lazar MA. Rev-erb $\alpha$ and Rev-erb $\beta$ coordinately protect the circadian clock and normal metabolic function. Genes Dev 26: 657-667, 2012.

9. Carter EL, Gupta N, and Ragsdale SW. High affinity heme binding to a heme regulatory motif on the nuclear receptor $\operatorname{Rev-erb} \beta$ leads to its degradation and indirectly regulates its interaction with nuclear receptor corepressor. $J$ Biol Chem 291: 2196-2222, 2016.

10. Carter EL and Ragsdale SW. Modulation of nuclear receptor function by cellular redox poise. J Inorg Biochem 133: 92-103, 2014.

11. Carter EL, Ramirez Y, and Ragsdale SW. The hemeregulatory motif of nuclear receptor $\operatorname{Rev}-\operatorname{erb} \beta$ is a key mediator of heme and redox signaling in circadian rhythm maintenance and metabolism. J Biol Chem 292: 1128011299, 2017.

12. Chen JJ and London IM. Regulation of protein-synthesis by heme-regulated EIF-2 $\alpha$ kinase. Trends Biochem Sci 20: 105-108, 1995.

13. Cho H, Zhao X, Hatori M, Yu RT, Barish GD, Lam MT, Chong L-W, DiTacchio L, Atkins AR, Glass CK, Liddle C, Auwerx J, Downes M, Panda S, and Evans RM. Regulation of circadian behaviour and metabolism by REVERB- $\alpha$ and REV-ERB- $\beta$. Nature 485: 123-127, 2012.

14. Cho Y, Gorina S, Jeffrey P, and Pavletich N. Crystal structure of a p53 tumor suppressor-DNA complex: understanding tumorigenic mutations. Science 265: 346$355,1994$.

15. Dace A, Zhao L, Park KS, Furuno T, Takamura N, Nakanishi M, West BL, Hanover JA, and Cheng S-Y. Hormone binding induces rapid proteasome-mediated degradation of thyroid hormone receptors. Proc Natl Acad Sci U S A 97: 8985-8990, 2000.

16. Davydov R, Fleischhacker AS, Bagai I, Hoffman BM, and Ragsdale SW. Comparison of the mechanisms of heme hydroxylation by heme oxygenases- 1 and-2: kinetic and cryoreduction studies. Biochemistry 55: 62-68, 2016.

17. Dioum EM, Rutter J, Tuckerman JR, Gonzalez G, Gilles-Gonzalez M-A, and McKnight SL. NPAS2: a gas-responsive transcription factor. Science 298: 23852387, 2002.

18. Dumas B, Harding HP, Choi HS, Lehmann KA, Chung M, Lazar MA, and Moore DD. A new orphan member of the nuclear hormone receptor superfamily closely related to Rev-Erb. Mol Endocrinol 8: 996-1005, 1994.

19. Faller M, Matsunaga M, Yin S, Loo JA, and Guo F. Heme is involved in microRNA processing. Nat Struct Mol Biol 14: 23-29, 2007.
20. Fleischhacker AS, Sharma A, Choi M, Spencer AM, Bagai I, Hoffman BM, and Ragsdale SW. The C-terminal heme regulatory motifs of heme oxygenase- 2 are redoxregulated heme binding sites. Biochemistry 54: 27092718, 2015.

21. Gabay C and Towne JE. Regulation and function of interleukin-36 cytokines in homeostasis and pathological conditions. J Leukoc Biol 97: 645-652, 2015.

22. Gardner JD, Yi L, Ragsdale SW, and Brunold TC. Spectroscopic insights into axial ligation and active-site $\mathrm{H}$ bonding in substrate-bound human heme oxygenase-2. $J$ Biol Inorg Chem 15: 1117-1127, 2010.

23. Gerhart-Hines Z, Feng D, Emmett MJ, Everett LJ, Loro E, Briggs ER, Bugge A, Hou C, Ferrara C, Seale P, Pryma DA, Khurana TS, and Lazar MA. The nuclear receptor Rev-erb $\alpha$ controls circadian thermogenic plasticity. Nature 503: 410-413, 2013.

24. Gibbs JE, Blaikley J, Beesley S, Matthews L, Simpson KD, Boyce SH, Farrow SN, Else KJ, Singh D, Ray DW, and Loudon ASI. The nuclear receptor REV-ERB $\alpha$ mediates circadian regulation of innate immunity through selective regulation of inflammatory cytokines. Proc Natl Acad Sci U S A 109: 582-587, 2012.

25. Glass CK and Rosenfeld MG. The coregulator exchange in transcriptional functions of nuclear receptors. Genes Dev 14: 121-141, 2000.

26. Guengerich FP. New trends in cytochrome P450 research at the half-century mark. J Biol Chem 288: 17063-17064, 2013.

27. Gupta N and Ragsdale SW. Thiol-disulfide redox dependence of heme binding and heme ligand switching in nuclear hormone receptor Rev-erb $\beta$. J Biol Chem 286: 4392-4403, 2011.

28. Hach A, Hon T, and Zhang L. A new class of repression modules is critical for heme regulation of the yeast transcriptional activator Hap1. Mol Cell Biol 19: 4324-4333, 1999.

29. Hamza I, Chauhan S, Hassett R, and O'Brian MR. The bacterial Irr protein is required for coordination of heme biosynthesis with iron availability. J Biol Chem 273: 21669-21674, 1998.

30. Hanna DA, Harvey RM, Martinez-Guzman O, Yuan X, Chandrasekharan B, Raju G, Outten FW, Hamza I, and Reddi AR. Heme dynamics and trafficking factors revealed by genetically encoded fluorescent heme sensors. Proc Natl Acad Sci U S A 113: 7539-7544, 2016.

31. Harding HP and Lazar MA. The monomer-binding orphan receptor Rev-Erb represses transcription as a dimer on a novel direct repeat. Mol Cell Biol 15: 4791-4802, 1995.

32. Hickman MJ and Winston F. Heme levels switch the function of Hap1 of Saccharomyces cerevisiae between transcriptional activator and transcriptional repressor. Mol Cell Biol 27: 7414-7424, 2007.

33. Hon T, Hach A, Lee HC, Cheng T, and Zhang L. Functional analysis of heme regulatory elements of the transcriptional activator Hap1. Biochem Biophys Res Commun 273: 584-591, 2000.

34. Hon T, Lee HC, Hu ZZ, Iyer VR, and Zhang L. The heme activator protein Hap1 represses transcription by a hemeindependent mechanism in Saccharomyces cerevisiae. Genetics 169: 1343-1352, 2005.

35. Hu RG, Wang HQ, Xia ZX, and Varshavsky A. The Nend rule pathway is a sensor of heme. Proc Natl Acad Sci U S A 105: 76-81, 2008. 
36. Huang TJ, McCoubrey WK, and Maines MD. Heme oxygenase- 2 interaction with metalloporphyrins: function of heme regulatory motifs. Antioxid Redox Signal 3: 685696, 2001.

37. Igarashi J, Sato A, Kitagawa T, Yoshimura T, Yamauchi S, Sagami I, and Shimizu T. Activation of heme-regulated eukaryotic initiation factor $2 \alpha$ kinase by nitric oxide is induced by the formation of a five-coordinate NO-heme complex: optical absorption, electron spin resonance, and resonance Raman spectral studies. J Biol Chem 279: 15752-15762, 2004.

38. Ishikawa $\mathrm{H}$, Kato $\mathrm{M}$, Hori $\mathrm{H}$, Ishimori $\mathrm{K}$, Kirisako $\mathrm{T}$, Tokunaga F, and Iwai K. Involvement of heme regulatory motif in heme-mediated ubiquitination and degradation of IRP2. Mol Cell 19: 171-181, 2005.

39. Ishikawa H, Nakagaki M, Bamba A, Uchida T, Hori H, O'Brian MR, Iwai $\mathrm{K}$, and Ishimori $\mathrm{K}$. Unusual heme binding in the bacterial iron response regulator protein: spectral characterization of heme binding to the heme regulatory motif. Biochemistry 50: 1016-1022, 2011.

40. Ishizuka $\mathrm{T}$ and Lazar MA. The N-CoR/histone deacetylase 3 complex is required for repression by thyroid hormone receptor. Mol Cell Biol 23: 5122-5131, 2003.

41. Iwai K, Klausner RD, and Rouault TA. Requirements for iron-regulated degradation of the RNA binding protein, iron regulatory protein 2. EMBO J 14: 5350-5357, 1995.

42. Jiang J, Westberg JA, and Andersson LC. Stanniocalcin 2, forms a complex with heme oxygenase 1, binds hemin and is a heat shock protein. Biochem Biophys Res Commun 421: 274-279, 2012.

43. Kaasik K and Chi Lee C. Reciprocal regulation of haem biosynthesis and the circadian clock in mammals. Nature 430: 467-471, 2004.

44. Kammler M, Schon C, and Hantke K. Characterization of the ferrous iron uptake system of Escherichia coli. J Bacteriol 175: 6212-6219, 1993.

45. Kim JY, Son YL, Kim J-S, and Lee YC. Molecular determinants required for selective interactions between the thyroid hormone receptor homodimer and the nuclear receptor corepressor N-CoR. J Mol Biol 396: 747-760, 2010.

46. Kitatsuji C, Izumi K, Nambu S, Kurogochi M, Uchida T, Nishimura SI, Iwai K, O'Brian MR, Ikeda-Saito M, and Ishimori K. Protein oxidation mediated by heme-induced active site conversion specific for heme-regulated transcription factor, iron response regulator. Sci Rep 6: 18703, 2016.

47. Ko $\mathrm{CH}$ and Takahashi JS. Molecular components of the mammalian circadian clock. Hum Mol Genet 15: R271R277, 2006.

48. Kubota Y, Nomura K, Katoh Y, Yamashita R, Kaneko K, and Furuyama K. Novel mechanisms for heme-dependent degradation of ALAS1 protein as a component of negative feedback regulation of heme biosynthesis. $\mathrm{J}$ Biol Chem 291: 20516-20529, 2016.

49. Kühl T, Sahoo N, Nikolajski M, Schlott B, Heinemann $\mathrm{SH}$, and Imhof D. Determination of hemin-binding characteristics of proteins by a combinatorial peptide library approach. Chembiochem 12: 2846-2855, 2011.

50. Kühl T, Wißbrock A, Goradia N, Sahoo N, Galler K, Neugebauer U, Popp J, Heinemann SH, Ohlenschläger O, and Imhof D. Analysis of $\mathrm{Fe}$ (III) heme binding to cysteine-containing heme-regulatory motifs in proteins. ACS Chem Biol 8: 1785-1793, 2013.
51. Kumar N, Solt LA, Wang Y, Rogers PM, Bhattacharyya G, Kamenecka TM, Stayrook KR, Crumbley C, Floyd ZE, Gimble JM, Griffin PR, and Burris TP. Regulation of adipogenesis by natural and synthetic REV-ERB ligands. Endocrinology 151: 3015-3025, 2010.

52. Lathrop JT and Timko MP. Regulation by heme of mitochondrial protein-transport through a conserved aminoacid motif. Science 259: 522-525, 1993.

53. Leichert LI, Gehrke F, Gudiseva HV, Blackwell T, Ilbert M, Walker AK, Strahler JR, Andrews PC, and Jakob U. Quantifying changes in the thiol redox proteome upon oxidative stress in vivo. Proc Natl Acad Sci U S A 105: 8197-8202, 2008.

54. Liu M, Tanaka WN, Zhu H, Xie G, Dooley DM, and Lei B. Direct hemin transfer from IsdA to IsdC in the iron-regulated surface determinant (Isd) heme acquisition system of Staphylococcus aureus. J Biol Chem 283: 6668-6676, 2008.

55. Maines MD. The heme oxygenase system: a regulator of second messenger gases. Annu Rev Pharmacol Toxicol 37: 517-554, 1997.

56. Maines MD, Trakshel GM, and Kutty RK. Characterization of two constitutive forms of rat-liver microsomal heme oxygenase: only one molecular-species of the enzyme is inducible. J Biol Chem 261: 411-419, 1986.

57. Mansuy D, Duppel W, Ruf HH, and Ullrich V. Phosphines as ligand to microsomal cytochrome-P450. Hoppe Seylers Z Physiol Chem 355: 1341-1349, 1974.

58. Marvin KA, Reinking JL, Lee AJ, Pardee K, Krause HM, and Burstyn JN. Nuclear receptors Homo sapiens Rev$\operatorname{erb} \beta$ and Drosophila melanogaster E75 are thiolateligated heme proteins which undergo redox-mediated ligand switching and bind $\mathrm{CO}$ and NO. Biochemistry 48: 7056-7071, 2009.

59. Matta-Camacho E, Banerjee S, Hughes TS, Solt LA, Wang Y, Burris TP, and Kojetin DJ. Structure of REV$\mathrm{ERB} \beta$ ligand-binding domain bound to a porphyrin antagonist. J Biol Chem 289: 20054-20066, 2014.

60. McCoubrey WK, Huang TJ, and Maines MD. Heme oxygenase- 2 is a hemoprotein and binds heme through heme regulatory motifs that are not involved in heme catalysis. J Biol Chem 272: 12568-12574, 1997.

61. Miki T, Matsumoto T, Zhao Z, and Lee CC. p53 regulates Period 2 expression and the circadian clock. Nat Commun 4: 2444, 2013.

62. Miksanova M, Igarashi J, Minami M, Sagami I, Yamauchi S, Kurokawa H, and Shimizu T. Characterization of hemeregulated eIF2 $\alpha$ kinase: roles of the $\mathrm{N}$-terminal domain in the oligomeric state, heme binding, catalysis, and inhibition. Biochemistry 45: 9894-9905, 2006.

63. Munakata H, Sun JY, Yoshida K, Nakatani T, Honda E, Hayakawa S, Furuyama K, and Hayashi N. Role of the heme regulatory motif in the heme-mediated inhibition of mitochondrial import of 5 -aminolevulinate synthase. $J$ Biochem 136: 233-238, 2004.

64. Nygaard TK, Blouin GC, Liu M, Fukumura M, Olson JS, Fabian M, Dooley DM, and Lei B. The mechanism of direct heme transfer from the streptococcal cell surface protein Shp to HtsA of the HtsABC transporter. J Biol Chem 281: 20761-20771, 2006.

65. Ogawa K, Sun J, Taketani S, Nakajima O, Nishitani C, Sassa S, Hayashi N, Yamamoto M, Shibahara S, Fujita H, and Igarashi K. Heme mediates derepression of Maf recognition element through direct binding to transcription repressor Bach1. EMBO J 20: 2835-2843, 2001. 
66. Pardee KI, Xu X, Reinking J, Schuetz A, Dong A, Liu S, Zhang R, Tiefenbach J, Lajoie G, Plotnikov AN, Botchkarev A, Krause HM, and Edwards A. The structural basis of gas-responsive transcription by the human nuclear hormone receptor REV-ERB $\beta$. PLoS Biol 7: e1000043, 2009.

67. Pfeifer K, Kim K-S, Kogan S, and Guarente L. Functional dissection and sequence of yeast HAP1 activator. Cell 56: 291-301, 1989.

68. Phelan CA, Gampe RT, Lambert MH, Parks DJ, Montana V, Bynum J, Broderick TM, Hu X, Williams SP, Nolte RT, and Lazar MA. Structure of Rev-erb $\alpha$ bound to NCoR reveals a unique mechanism of nuclear receptor-corepressor interaction. Nat Struct Mol Biol 17: 808-814, 2010.

69. Qi Z, Hamza I and O'Brian MR. Heme is an effector molecule for iron-dependent degradation of the bacterial iron response regulator (Irr) protein. Proc Natl Acad Sci U S A 96: 13056-13061, 1999.

70. Raghuram S, Stayrook KR, Huang P, Rogers PM, Nosie AK, McClure DB, Burris LL, Khorasanizadeh S, Burris $\mathrm{TP}$, and Rastinejad F. Identification of heme as the ligand for the orphan nuclear receptors REV-ERB $\alpha$ and REVERB $\beta$. Nat Struct Mol Biol 14: 1207-1213, 2007.

71. Ragsdale SW and Yi L. Thiol/disulfide redox switches in the regulation of heme binding to proteins. Antioxid Redox Signal 14: 1039-1047, 2011.

72. Raspé E, Duez H, Mansén A, Fontaine C, Fiévet C, Fruchart J-C, Vennström B, and Staels B. Identification of Rev-erb $\alpha$ as a physiological repressor of apoC-III gene transcription. J Lipid Res 43: 2172-2179, 2002.

73. Reppert SM and Weaver DR. Coordination of circadian timing in mammals. Nature 418: 935-941, 2002.

74. Robbins AH and Stout CD. Structure of activated aconitase: formation of the [4Fe-4S] cluster in the crystal. Proc Natl Acad Sci U S A 86: 3639-3643, 1989.

75. Ruf HH and Wende P. Hyperporphyrin spectra of ferric dimercaptide hemin complexes: models for ferric cytochrome P450-thiol complexes. J Am Chem Soc 99: 5499-5500, 1977.

76. Sancar A. Regulation of the mammalian circadian clock by cryptochrome. J Biol Chem 279: 34079-34082, 2004.

77. Schubert E, Florin N, Duthie F, Brewitz HH, Kühl T, Imhof D, Hagelueken G, and Schiemann O. Spectroscopic studies on peptides and proteins with cysteine-containing heme regulatory motifs (HRM). J Inorg Biochem 148: 4956, 2015.

78. Schuller DJ, Wilks A, de Montellano PRO, and Poulos TL. Crystal structure of human heme oxygenase-1. Nat Struct Biol 6: 860-867, 1999.

79. Shen J, Sheng X, Chang Z, Wu Q, Wang S, Xuan Z, Li D, Wu Y, Shang Y, Kong X, Yu L, Li L, Ruan K, Hu H, Huang Y, Hui L, Xie D, Wang F, and Hu R. Iron metabolism regulates $\mathrm{p} 53$ signaling through direct heme-p53 interaction and modulation of p53 localization, stability, and function. Cell Rep 7: 180-193, 2014.

80. Spencer ALM, Bagai I, Becker DF, Zuiderweg ERP, and Ragsdale SW. Protein/protein interactions in the mammalian heme degradation pathway: heme oxygenase-2, cytochrome $\mathrm{P} 450$ reductase, and biliverdin reductase. $J$ Biol Chem 289: 29836-29858, 2014.

81. Strickland S, Palmer G, and Massey V. Determination of dissociation constants and specific rate constants of enzyme-substrate (or protein-ligand) interactions from rapid reaction kinetic data. J Biol Chem 250: 4048-4052, 1975.

82. Sun JY, Hoshino H, Takaku K, Nakajima O, Muto A, Suzuki H, Tashiro S, Takahashi S, Shibahara S, Alam J, Taketo MM, Yamamoto M, and Igarashi K. Hemoprotein Bach1 regulates enhancer availability of heme oxygenase1 gene. EMBO J 21: 5216-5224, 2002.

83. Sun SF, Sono M, and Dawson JH. Mono- and bisphosphine-ligated $\mathrm{H} 93 \mathrm{G}$ myoglobin: spectral models for ferrous-phosphine and ferrous-CO cytochrome P450. $J$ Inorg Biochem 127: 238-245, 2013.

84. Sundaramoorthy M, Terner J, and Poulos TL. The crystal structure of chloroperoxidase: a heme peroxidase-cytochrome P450 functional hybrid. Structure 3: 1367-1377, 1995.

85. Suzuki H, Tashiro S, Hira S, Sun JY, Yamazaki C, Zenke Y, Ikeda-Saito M, Yoshida M, and Igarashi K. Heme regulates gene expression by triggering $\mathrm{Crm} 1$-dependent nuclear export of Bach1. EMBO J 23: 2544-2553, 2004.

86. Varfaj F, Lampe JN, and de Montellano PRO. Role of cysteine residues in heme binding to human heme oxygenase-2 elucidated by two-dimensional NMR spectroscopy. J Biol Chem 287: 35181-35191, 2012.

87. Vukomanovic D, Rahman MN, Maines MD, Ozolins TRS, Szarek WA, Jia ZJ, and Nakatsu K. Cysteineindependent activation/inhibition of heme oxygenase- 2 . Med Gas Res 6: 10-13, 2016.

88. Wang $\mathbf{J}$ and Lazar MA. Bifunctional role of Rev-erb $\alpha$ in adipocyte differentiation. Mol Cell Biol 28: 22132220, 2008.

89. Wang J, Li Y, Zhang M, Liu Z, Wu C, Yuan H, Li Y-Y, Zhao X, and Lu H. A zinc finger HIT domain-containing protein, ZNHIT-1, interacts with orphan nuclear hormone receptor Rev-erb $\beta$ and removes Rev-erb $\beta$-induced inhibition of apoCIII transcription. FEBS J 274: 53705381, 2007.

90. Wang J, Liu N, Liu Z, Li Y, Song C, Yuan H, Li Y-y, Zhao X, and Lu H. The orphan nuclear receptor Rev-erb $\beta$ recruits Tip60 and HDAC1 to regulate apolipoprotein CIII promoter. Biochim Biophys Acta 1783: 224-236, 2008.

91. Wang J, Yin L, and Lazar MA. The orphan nuclear receptor Rev-erb $\alpha$ regulates circadian expression of plasminogen activator inhibitor type 1. J Biol Chem 281: 33842-33848, 2006.

92. Wang TA, Yu YV, Govindaiah G, Ye X, Artinian L, Coleman TP, Sweedler JV, Cox CL, and Gillette MU. Circadian rhythm of redox state regulates excitability in suprachiasmatic nucleus neurons. Science 337: 839-842, 2012.

93. Woo E-J, Jeong DG, Lim M-Y, Kim SJ, Kim K-J, Yoon S-M, Park B-C, and Ryu SE. Structural insight into the constitutive repression function of the nuclear receptor Rev-erb $\beta$. J Mol Biol 373: 735-744, 2007.

94. Yang J, Kim KD, Lucas A, Drahos KE, Santos CS, Mury SP, Capelluto DGS, and Finkielstein CV. A novel hemeregulatory motif mediates heme-dependent degradation of the circadian factor Period 2. Mol Cell Biol 28: 46974711, 2008.

95. Yang J, Panek HR, and O'Brian MR. Oxidative stress promotes degradation of the Irr protein to regulate haem biosynthesis in Bradyrhizobium japonicum. Mol Microbiol 60: 209-218, 2006.

96. Yang JH, Ishimori K, and O'Brian MR. Two heme binding sites are involved in the regulated degradation of the bacterial iron response regulator (Irr) protein. $J$ Biol Chem 280: 7671-7676, 2005. 
97. Yang JH, Sangwan I, Lindemann A, Hauser F, Hennecke H, Fischer HM, and O'Brian MR. Bradyrhizobium japonicum senses iron through the status of haem to regulate iron homeostasis and metabolism. Mol Microbiol 60: 427-437, 2006.

98. Yi L, Jenkins PM, Leichert LI, Jakob U, Martens JR, and Ragsdale SW. Heme regulatory motifs in heme oxygenase- 2 form a thiol/disulfide redox switch that responds to the cellular redox state. J Biol Chem 284: 20556-20561, 2009.

99. Yi L and Ragsdale SW. Evidence that the heme regulatory motifs in heme oxygenase- 2 serve as a thiol/disulfide redox switch regulating heme binding. J Biol Chem 282: 21056-21067, 2007.

100. Yin L, Joshi S, Wu N, Tong X, and Lazar MA. E3 ligases Arf-bp1 and Pam mediate lithium-stimulated degradation of the circadian heme receptor Rev-erb $\alpha$. Proc Natl Acad Sci U S A 107: 11614-11619, 2010.

101. Yin L, Wang J, Klein PS, and Lazar MA. Nuclear receptor Rev-erb $\alpha$ is a critical lithium-sensitive component of the circadian clock. Science 311: 1002-1005, 2006.

102. Yin L, Wu N, Curtin JC, Qatanani M, Szwergold NR, Reid RA, Waitt GM, Parks DJ, Pearce KH, Wisely GB, and Lazar MA. Rev-erb $\alpha$, a heme sensor that coordinates metabolic and circadian pathways. Science 318: 17861789, 2007.

103. Zenke-Kawasaki Y, Dohi Y, Katoh Y, Ikura T, Ikura M, Asahara T, Tokunaga F, Iwai K, and Igarashi K. Heme induces ubiquitination and degradation of the transcription factor Bach1. Mol Cell Biol 27: 6962-6971, 2007.

104. Zhang H, Chen YQ, Keane FM, and Gorrell MD. Advances in understanding the expression and function of dipeptidyl peptidase 8 and 9. Mol Cancer Res 11: 1487-1496, 2013.

105. Zhang L and Guarente L. Heme binds to a short sequence that serves a regulatory function in diverse proteins. EMBO J 14: 313-320, 1995.

106. Zhang L and Hach A. Molecular mechanism of heme signalling in yeast: the transcriptional activator Hap1 serves as the key mediator. Cell Mol Life Sci 56: 415-426, 1999.

Address correspondence to: Dr. Stephen W. Ragsdale Department of Biological Chemistry University of Michigan

1150 W. Medical Center Dr, 5220D MSRBIII Ann Arbor, MI 48109

E-mail: sragsdal@umich.edu
Date of first submission to ARS Central, September 12, 2017; date of acceptance, October 5, 2017.

\begin{tabular}{|c|}
\hline 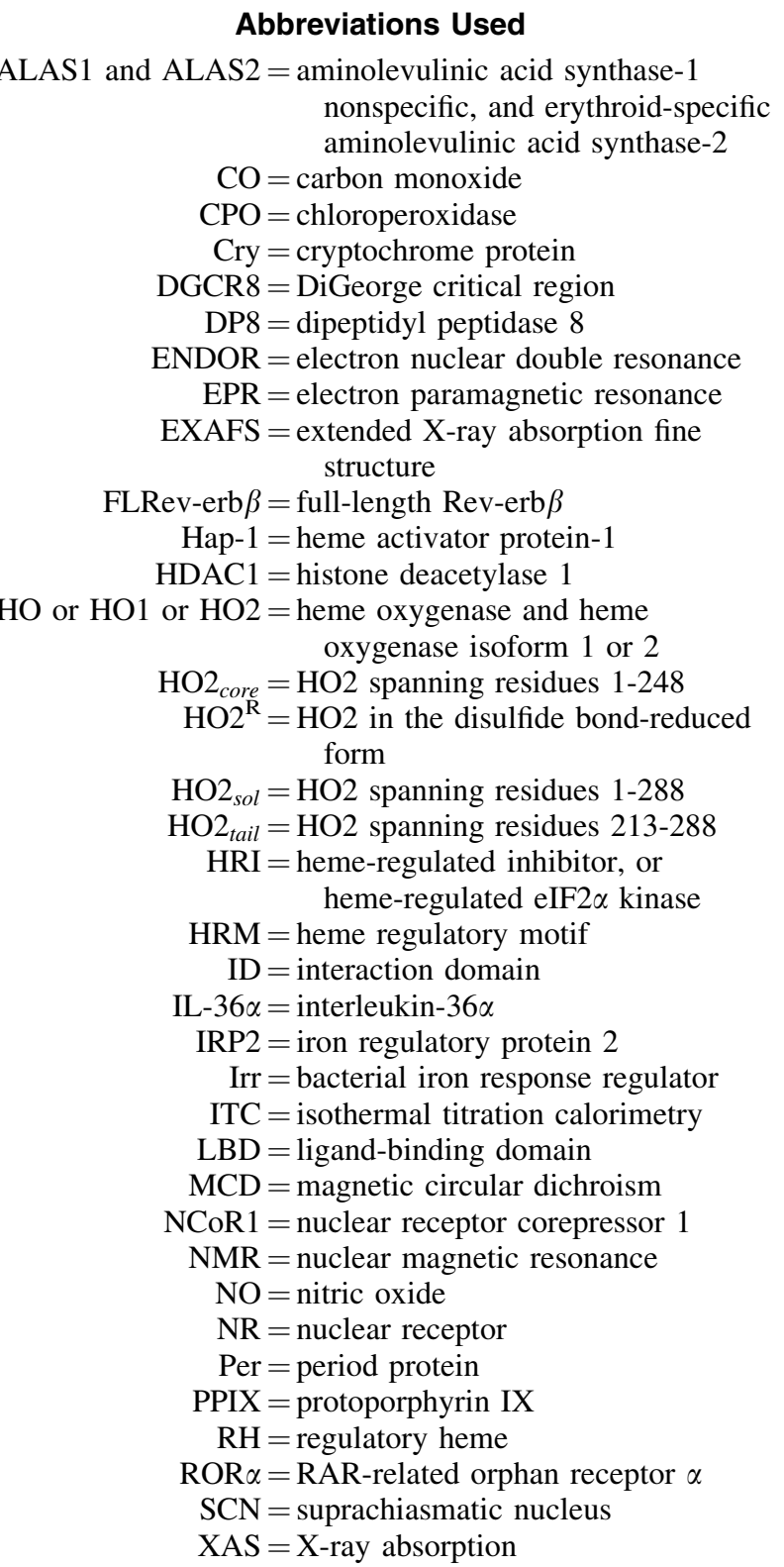 \\
\hline
\end{tabular}

